\title{
Hydrodynamic Modelling of a Flood-Prone Tidal River Using the 1D Model MIKE HYDRO River: Calibration and Sensitivity Analysis
}

\author{
Mahsa Jahandideh-Tehrani ${ }^{\mathrm{a}^{*}}$, Fernanda Helfer ${ }^{\mathrm{a}}$, Hong Zhang ${ }^{\mathrm{a}}$, Graham Jenkins ${ }^{\mathrm{a}}$, Yingying $\mathrm{Yu}^{\mathrm{b}}$ \\ a School of Engineering, Griffith University, Australia \\ ${ }^{\mathrm{b}}$ CSIRO Land and Water, Canberra, Australia
}

\begin{abstract}
Hydrodynamic modeling is a powerful tool to gain understanding of river conditions. However, as widely known, models vary in terms of how they respond to changes and uncertainty in their input parameters. A hydrodynamic river model (MIKE HYDRO River) was developed and calibrated for a flood-prone tidal river located in South East Queensland, Australia. The model was calibrated using Manning's roughness coefficient for the normal dry and flood periods. The model performance was assessed by comparing observed and simulated water level, and estimating performance indices. Results indicated a satisfactory agreement between the observed and simulated results. The hydrodynamic modelling results revealed that the calibrated Manning's roughness coefficient ranged between 0.011-0.013. The impacts of tidal variation at the river mouth and the river discharge from upstream are the major driving force for the hydrodynamic process. To investigate the impacts of the boundary conditions, a new sensitivity analysis approach, based on adding stochastic terms (random noise) to the time series of boundary conditions, was conducted. The main purpose of such new sensitivity analysis was to impose changes in magnitude and time of boundary conditions randomly, which is more similar to the real and natural water level variations compared to impose constant changes of water level. In this new approach, the possible number of variations in simulated results was separately evaluated for both downstream and upstream boundaries under $5 \%, 10 \%$, and $15 \%$ perturbation. The sensitivity analysis results revealed that in the river under study, the middle parts of the river were shown to be more sensitive to downstream
\end{abstract}

\footnotetext{
* Corresponding author. Address: Griffith School of Engineering, Gold Coast Campus, Griffith University, QLD 4222 , Australia.

E-mail address: mahsa.jahandideh-tehrani@griffithuni.edu.au
} 
boundary condition as maximum water level variations can reach $8 \%, 12 \%$, and $15 \%$ under $5 \%$, $10 \%$, and $15 \%$ changes in the downstream boundary, respectively. The outcomes of the present paper will benefit future modeling efforts through provision of a robust tool to enable prediction of water levels at ungauged points of the river under various scenarios of flooding and climate change for the purpose of city planning and decision making.

Keywords: river model; MIKE HYDRO; Manning's roughness coefficient; random noise; boundary condition

\section{Introduction}

Floods are one of the most frequent natural hazards and have led to human losses, large economic losses, the destruction of fertile land, and damages to properties and infrastructure (Douben 2006; Mahmood et al. 2019). Among all natural disasters occurring in Australia, flooding causes the most damage. The coastal regions of south eastern Queensland and northern New South Wales (where important urban centers, such as the Gold Coast and Brisbane, are located) are the most flood-prone areas, yet are also the regions with the highest population growth in the country (Abbs et al. 2007; Brunton et al. 2018). During the last 120 years, more than 40 cyclones have hit the Gold Coast City (Mirfenderesk 2009), bringing high intensity rainfall, causing floods, damage and destruction. The Nerang River, is a tidal river encountering many flooding events, storm surges, and flood inundations (GCCC 2006). In order to minimize the losses of flooding events and to plan flood control operations, river hydrodynamic modeling is essential. The accurate simulation of river flow is an important task in river modelling since open channel flow is usually turbulent (Wu et al. 2000; Vidal et al. 2005). Additionally, sea level variations due to climate change impacts can potentially affect the hydraulic conditions, storm surges, and extreme flow events along the tidal limit of the rivers (Islam et al. 2018). Therefore, in a tidal river, the development of a hydrodynamic river model is significantly helpful to address the probable damages of water level variations and flooding events as a result of sea level rise/variations under climate change (Islam et al. 2018). 
Hydrodynamic models are mathematical models that provide a physical basis for simulating a wide range of flow situations and sediment transport. These models simulate water movement by solving governing equations, which are formulated based on the laws of physics (Teng et al. 2017). St.Venant equations are applied to calculate the space-time variation of water level and flow in rivers (Strelkoff 1970; Tayfur et al. 1993; Wang et al. 2000; Kim et al. 2019). Channel roughness is a significant parameter for calibrating and validating hydrodynamic models, which plays a crucial role in the modelling of natural rivers (Ardiçlıoğlu \& Kuriqi 2019). Channel roughness represents the amount of frictional resistance water experiences when passing over channel features, which can be accounted by the Manning's Roughness Coefficient. This coefficient is a highly variable parameter, and its magnitude depends on particle size, vegetation cover, channel alignment, channel irregularities, meandering, and other river characteristics (Vijay et al. 2007; Parhi et al. 2012). Accurate estimation of the channel roughness coefficient is vital to minimize modelling and simulation errors. As a very sensitive parameter, it is common to calibrate hydrodynamic models for this coefficient (Boulomytis et al. 2017), which is mostly calibrated using observed water levels (Pappenberger et al. 2005; Wang et al. 2010). Considering the significant sensitivity of this parameter, it has been widely selected as a calibration parameter, and manually calibrated in hydrodynamic modeling approaches (Panda et al. 2010; Islam et al. 2018; Kumar 2018). Over the manual calibration, the simulation and observed data are compared for different values of channel roughness until the satisfactory match between model response and historical data is obtained (Panda et al. 2010). Besides the manual calibration, automatic calibration is another technique, which is defined as parameter adjustment based on a specified search scheme optimizing numerical measures of goodness of fit of the model results to the data (Dung et al. 2011). Automatic calibration procedures are mainly based on optimization tools, such as evolutionary algorithms (e.g., genetic algorithm, differential evolution, and Shuffled complex evolution (Jahandideh-Tehrani et al. 2019)) and the classical gradient-based approaches (e.g., the Gauss-Levenberg-Marquardt method) (Fabio et al. 2010). Despite the extensive applications of automatic calibration in hydrological models, these techniques have been limitedly employed in hydrodynamic models due to lack of required data (e.g., discharge data over flooding 
events) and high computational demand (Fabio et al. 2010). Therefore, manual calibration is normally mentioned as the standard for hydrodynamic modellings (Dung et al. 2011).

In addition to the channel roughness, the boundary conditions have significant impacts on the simulation results. Basically, model inputs (e.g., boundary conditions and initial conditions) are considered as the main sources of uncertainty, which leads to differences of a model outcome with reality (Warmink et al. 2011). In order to quantify and address the uncertainty of a model, a sensitivity analysis should be implemented to identify the sensitivity of different river locations to model input uncertainties. In order to address the uncertainty, the response of a model performance to a range of variations in model inputs should be investigated. Therefore, boundary conditions should be studied for the sake of evaluating the sensitivity of the model. To be more exact, a sensitivity analysis is essential in order to explore and quantify the influence of possible changes in boundary conditions on model output and system performance indices (Hall et al. 2009; Wang et al. 2019). As a result, analysts gain a better idea of the sensitivity of the model to input parameters, and thus can find out how the outputs depend on the certain inputs (Whitehead \& Young 1979; Tsai et al. 2017; Xu et al. 2019).

Many studies have performed sensitivity analysis using regular perturbations of input parameters, and by making changes in input data by a given percentage (Norton \& Bradford 2009; Sun et al. 2012; De Paiva et al. 2013; Sarvia et al. 2017; Bruce et al. 2018; Islam et al. 2018). In this way, a constant perturbation is imposed on input data; However, constant perturbation of input parameters is not the indication of the real variability of input parameters in the real environment. In order to do a quantitative measurement which indicates the real variability of a hydrological times series, several approaches have been developed, including the 'partial derivatives' method (Dimopoulos et al. 1999), the 'weights' method (Garson 1991), the 'perturbation' method (Scardi \& Harding 1999), and the 'profile' method (Lek et al. 1996). The perturbation method, which is one of the most widely used, is based on perturbation of inputs and reporting the corresponding changes in the model outputs. This perturbation is imposed by adding random noise to specific input data of a model (Bai et al. 2011). This random noise is called the stochastic terms, which consists of random variables. Bai et al. (2011) applied this sensitivity analysis approach to transform the deterministic 
model variable into stochastic variables, and to evaluate the parameter uncertainties of a water quality model. They concluded that model input shows more sensitivity than model parameters.

Among the literature review in the realm of water resources, sensitivity analysis based on using stochastic terms for representing the sensitivity of input boundary conditions are less common (Moradkhani et al. 2005; Herrnegger et al. 2015). Additionally, no studies have applied this sensitivity analysis method to any hydrodynamic river model. This sensitivity analysis approach is applied in our hydrodynamic model by combining stochastic terms with input boundary conditions. The randomness of changes in magnitude and time is the main feature of this method (Radwan et al. 2004), and what makes this approach distinct. The main advantage of this approach lies in its ability to create a real condition in a river model as variability of boundary conditions is random in a real river rather than being constant.

Given the numerous occurrences of flooding events in the Nerang River catchment, hydrodynamic modeling of this river flow is necessary, so discharges are better predicted at ungauged points of the river, and flooding hazards can be minimized, under flooding conditions. The current paper presents the 1D hydrodynamic modeling set-up of the Nerang River along its tidal limit using MIKE HYDRO River software. The modelling set-up consisted of three main steps: (1) model calibration; (2) model validation; and (3) sensitivity analysis of boundary conditions. During the first step, input data, initial conditions, boundary conditions, adjusted cross sections, and time steps were defined for the model. The model was calibrated using hourly water level data over the year 2012 . The parameter Manning's roughness coefficient was chosen for calibration. In order to evaluate model performance, three performance indices were used to compare observed and simulated results. In order to investigate the impacts of variations of boundary conditions, a new application of sensitivity analysis was carried out by adding stochastic terms (random noise) to water level time series of each boundary condition separately. The aim of adding random values to water level time series was to impose random changes in terms of time and magnitude. While many studies conducted sensitivity analysis based on imposing constant and specific percentage of changes to data time series of hydrodynamic models, the current research focused on applying the new sensitivity analysis approach to the boundary conditions of hydrodynamic river models as this new approach can 
potentially generate more real and natural probable variations in water level. Six scenarios were defined for sensitivity analysis by adding stochastic terms to the water level time series of each boundary condition. The six assumed scenarios were defined according to the changes in the downstream boundary of (1) $5 \%$, (2) $10 \%$, and (3) $15 \%$; and the upstream boundary of (4) $5 \%$, (5) $10 \%$, and (6) $15 \%$. The amounts of possible variations were evaluated by comparing the water level conditions before and after imposing the random noise changes. This comparison was made in two steps. First, the sensitivity analysis performance indices were assessed by comparing the simulated results of six scenarios with the observed water level data at a gauged point of the river. The second step was to compare the distributions of water level changes under the six scenarios, and at three distinct locations along the Nerang River.

\section{Study domain}

The Nerang River catchment is the largest catchment in the Gold Coast region, Queensland, Australia. It lies between latitude $28^{\circ} 14^{\prime} \mathrm{S}$ to $27^{\circ} 58^{\prime} \mathrm{S}$, and longitude $153^{\circ} 15^{\prime} \mathrm{E}$ to $153^{\circ} 25^{\prime} \mathrm{E}$. The Nerang River, located in the center of the Gold Coast region, is approximately $62 \mathrm{~km}$ long and flows from the McPherson Range and Springbrook Plateau and reaches its mouth in the Gold Coast Broadwater at Southport. The Nerang River catchment covers an area of $493.3 \mathrm{~km}^{2}$ (Figure 1). The Nerang River consists of several waterways, and the total length of the waterways network is $928 \mathrm{~km}$ where the Nerang River is the main waterway (GCCC 2011). The topography of the catchment changes from steep hills and mountainous terrain in the upper catchment to wide, flat floodplains at the river mouth and canal areas. Catchment elevations varies from $1150 \mathrm{~m}$ in McPherson Ranges to less than $2 \mathrm{~m}$ in lower reaches of the river (GCCC 2015). The average mean monthly flow of the river at Glenhurst gauging site (Figure 1) is $0.01 \mathrm{~m}^{3}$ per month (GCCC 2007). Two dams are situated along the Nerang River - the Hinze Dam and the Little Nerang Dam - which supply drinking water to the Gold Coast dwellers. The Nerang River catchment can be divided into three sub-catchments: the upper, middle, and lower reaches [38]. These three areas are distinguished by specific topography and land use. The lower Nerang River catchment is characterized by increasing urban development. This lower reach is surrounded by many residential 
buildings, and industrial and tourist centres. This populated area has been always in danger of probable flooding events. For instance, a peak flood of almost $1899 \mathrm{~m}^{3} / \mathrm{s}$ was recorded in 1974 over the observation period 1968-2018. The highest recorded water level corresponding to this event was 10.22 $m$ (BOM 2017).

The present paper focuses on the lower Nerang River catchment, which is also the tidal limit of this river, and the most susceptible region to flooding. To define the upstream and downstream river conditions, two monitoring sites were selected, the Glenhusrt site (22.7 $\mathrm{km}$ away from the river mouth) and the Gold Coast Seaway (at the river mouth) as marked in Figure 1. The average monthly discharge and water level at the Glenhurst site over 1968-2018 is indicated in Figure 2. As can be seen, the Nerang River has high discharge and water level from January to June (wet season), while low rate of discharge and water level is observed from July to December (dry season). Additionally, the highest average discharge (almost $6 \mathrm{~m}^{3} / \mathrm{s}$ ) and water level (almost $0.7 \mathrm{~m}$ ) occurred in February, whereas September recorded the lowest rate of both discharge $\left(0.3 \mathrm{~m}^{3} / \mathrm{s}\right)$ and water level $(0.4 \mathrm{~m})$. 


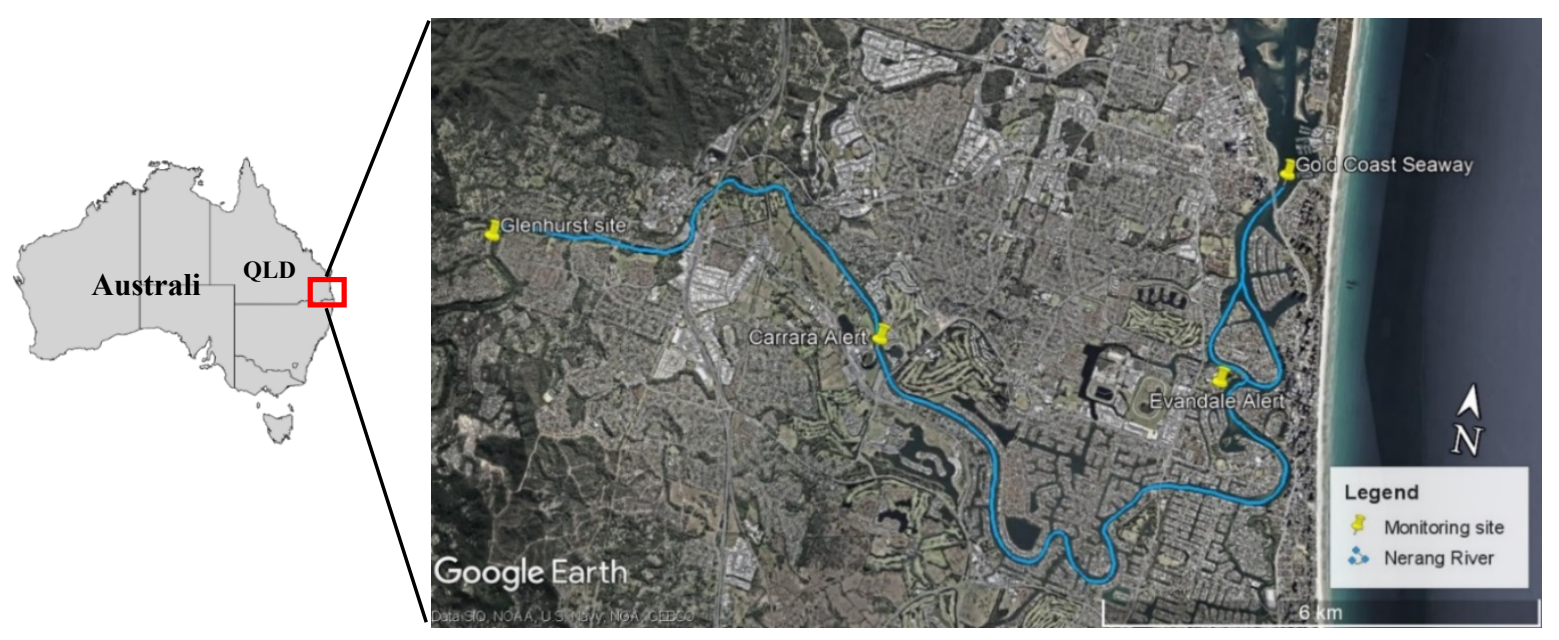

Figure 1. The Nerang River, its location in Australia and Queensland, and water level monitoring sites used in this study

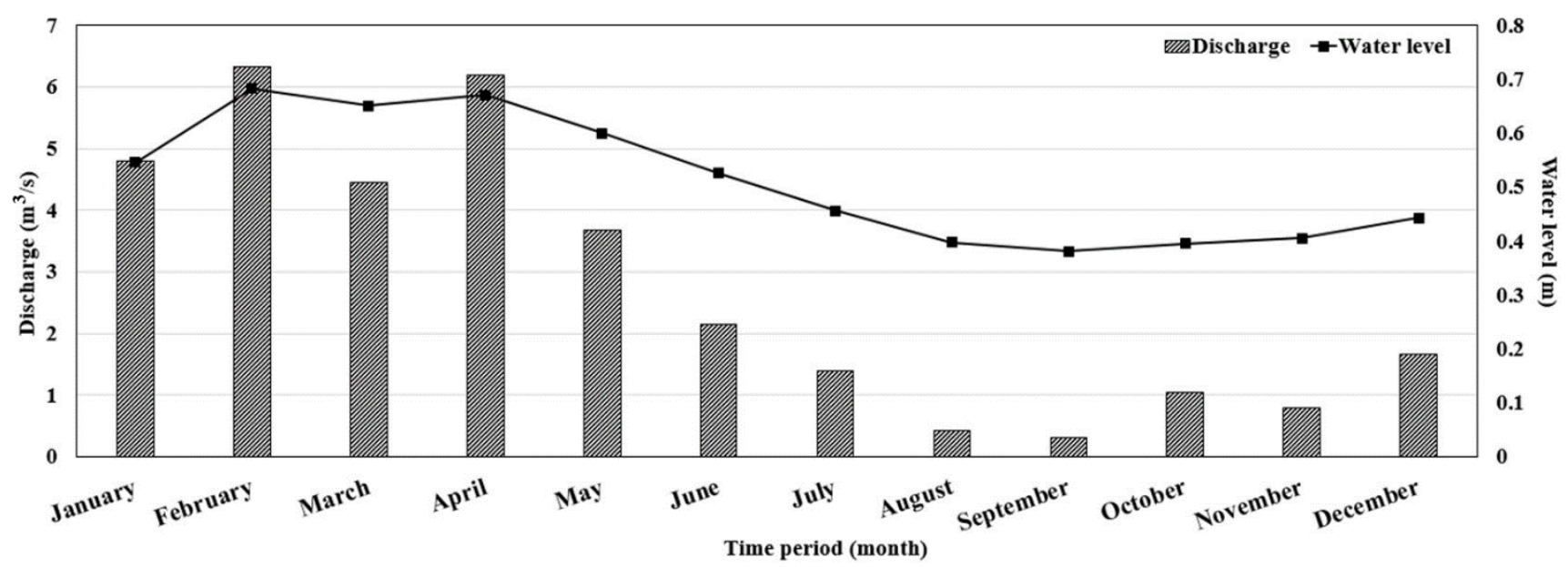

Figure 2. The average monthly discharge and water level at the Glenhurst site over 19682018

In the present paper, the lower Nerang River, dominated by tide motion from the tidal limit to the river mouth, has been selected for study. Hourly water level data at the Glenhurst monitoring site (22.7 $\mathrm{km}$ away from the river mouth) and hourly tide data at the Gold Coast Seaway for the year 2012 were collected from The Queensland Government Water Monitoring Information Portal (WMIP) and the Bureau of Meteorology (BOM), and were used as the upstream and downstream boundary conditions, respectively, in the hydrodynamic model (Figure 1).

In order to calibrate and Validate the model, unregulated water level records of the Carrara Alert Station (14.7 km away from mouth river, Figure 1) and hourly water level records of the Evandale Alert station (3.8 $\mathrm{km}$ away from mouth river, Figure 1) have been obtained respectively from the Department 
of Environment and Resources Management (DERM) and the Bureau of Meteorology (BOM) of the Australian Government for Queensland (Figure 1). The Evandale Alert station has limited data (only a five-day period) in the year 2012, and the Carrara Alert Station has data recorded over the entire year 2012. Hydrodynamic river models need river cross section data, in which the topographic elevations were obtained from DEM data. For Australian rivers, the Australian Government Geoscience Australia provides this data. The DEM of the study domain with a grid size of five meters was utilized to depict the topography level along the Nerang River.

\section{Hydrodynamic river modelling using MIKE HYDRO}

Hydrodynamic models can potentially perform river flow simulation at one dimensional (1D) or two/three dimensional (2D/3D) levels (Teng et al. 2017). Each of the stated model is associated with both advantages and disadvantages as shown in Table 1. The decision on selecting the applied dimension in hydrodynamic model depends on the case study, the scale, spatial resolution, required output, and available field data (model input data) (Leandro et al. 2009). Despite the development of 2D/3D models, 1D hydrodynamic models are still significantly useful due to their accuracy in describing the hydraulic behavior of natural streams and rivers as well as requirement of low computation time and relatively scare field data (Chen \& Liu, 2017). However, as can be seen in Table $1,2 \mathrm{D} / 3 \mathrm{D}$ models are more capable of representing detailed river bathymetry and topography and simulating the hydrodynamic conditions in complex river systems (Chen \& Liu, 2017). On the other hand, Bates (2004) confirmed that if high-resolution topographic data is used, 1D models are able to simulate river flow and flood propagation accurately in larger stream domains and over long periods of time. Merwade et al. (2008) discussed that 2D/3D hydrodynamic modeling approaches are efficient for flood inundation mapping. Regarding that the purpose of the current research is to calibrate and validate a river hydrodynamic model for evaluating the water level at ungauged points of the river rather than flood inundation analysis, the 1D modeling approach has been selected. Additionally, concerning the low computation time, limited available input data, and non-complex river system, the 1D approach has been a preferred tool. 
Table 1. Comparison of 1D, 2D, and 3D modelling approach

\begin{tabular}{|c|c|c|}
\hline Modelling approach & Advantages & Disadvantages \\
\hline One dimensional (1D) & $\begin{array}{l}\text { - Low computation time } \\
\text { - Low data requirement } \\
\text { - Low cost } \\
\text { - Accurate in modeling the large and non- } \\
\text { complex natural streams and rivers }\end{array}$ & $\begin{array}{l}\text { - Poor efficiency in complex } \\
\text { river system and topography } \\
\text { - Poor efficiency in complex } \\
\text { artificial channels } \\
\text { - Failure for provision of detailed } \\
\text { information }\end{array}$ \\
\hline $\begin{array}{l}\text { Two/three dimensional } \\
\text { (2D)/(3D) }\end{array}$ & $\begin{array}{l}\text { - Accurate bathymetric representation } \\
\text { - Accurate flood inundation mapping } \\
\text { - More efficiency in artificial channel } \\
\text { modelling } \\
\text { - Provision of outputs with higher } \\
\text { temporal and spatial resolution }\end{array}$ & $\begin{array}{l}\text { - High computation time } \\
\text { - High data requirement } \\
\text { - Time-consuming setup } \\
\text { - High cost }\end{array}$ \\
\hline
\end{tabular}

The hydrodynamic model chosen for the current study was the 1D MIKE HYDRO model (a new proposed version of MIKE 11), which is able to simulate unsteady flow in rivers and floodplains in shallow water types (DHI 2016). MIKE HYDRO River contains different modules, including HD (hydrodynamic), which is used for computing unsteady flow, discharge, and water level in rivers and floodplains in shallow water types (DHI 2016). Rahman et al. (2011) demonstrated that MIKE HD model require smaller run times, and the stability of this model is less sensitive to specified initial conditions compared to other hydraulic models (e.g., HEC-RAS). Therefore, regarding the satisfactory performance in hydrodynamic modeling approach and capability to simulate the hydrodynamic conditions of a tidal river with low data requirement, more model stability, and low computation time, MIKE HD has been selected for the current research.

The HD module of the MIKE HYDRO model calculates flow based on the following assumptions (DHI 2016):

- The flow is one dimension, which means that velocity and depth only change in the longitudinal direction of the channel.

- Water is homogenous; the water density variation is negligible.

- The bottom slope of the channel is small

- The wavelengths are large in comparison with the water depth; thus, the flow have a direction parallel to the bottom.

The MIKE HYDRO model is a fully dynamic model, which solves the St-Venant governing equation using a one-dimensional, implicit, finite difference scheme, as follows: 


$$
\begin{gathered}
\frac{\partial Q}{\partial x}+\frac{\partial A}{\partial t}=q \\
\frac{\partial Q}{\partial t}+\frac{\partial}{\partial x}\left(\alpha \frac{Q^{2}}{A}\right)+g A \frac{\partial h}{\partial x}+\frac{n^{2} g|Q|}{A R^{4 / 3}}=0
\end{gathered}
$$

where $Q=$ discharge $\left(\mathrm{m}^{3} / \mathrm{s}\right) ; A=$ cross section flow area $\left(\mathrm{m}^{2}\right) ; q=$ lateral inflow $\left(\mathrm{m}^{2} / \mathrm{s}\right) ; h=$ water level above a reference datum $(m) ; x=$ downstream direction $(m) ; t=$ time $(s) ; n=$ Manning resistance coefficient $\left(\mathrm{s} / \mathrm{m}^{1 / 3}\right) ; R=$ hydraulic or resistance radius $(\mathrm{m}) ; \mathrm{g}=$ gravity acceleration $\left(\mathrm{m}^{2} / \mathrm{s}\right) ;$ and $\alpha=$ momentum distribution coefficient (DHI 2016).

\section{Sensitivity analysis of boundary conditions}

Sensitivity analysis is of great importance to evaluate and quantify the uncertainties of river models, including boundary conditions uncertainties. The response of the model performance to a range of variations in boundary conditions and sensitivity of different locations (along the river) to these changes should be analyzed to address the uncertainties. In the present study, the key input variables are the boundary conditions at the Glenhurst site (upstream boundary) and the Gold Coast Seaway (downstream boundary) (Figure 1). Considering the highly seasonal variations, and nonlinear and noise features of the hydrological time series, the sensitivity analysis was investigated based on adding random noise to input boundary conditions of the hydrodynamic model. This additive stochastic term was defined by randomness changes in the time and magnitude of the water level time series for both downstream and upstream boundaries separately:

$$
X(t)=x(t)+\varepsilon(t)
$$

where $X(t)=$ changed water level data of each boundary condition at the $t$ th time step $(m) ; x(t)$ $=$ observed water level data of each boundary condition at the $t$ th time step $(m)$; and $\varepsilon(t)=$ generated random numbers at the $t$ th time step $(m)$. Matlab software has been used for generating random numbers which are defined as normalized values (between 0 and 1) that are drawn from a uniform distribution. To generate the random numbers within a specified range, it was essential to define the 
lower and upper limits. These limits have been defined according to the three different percentages of changes, which has applied for each boundary condition, 5\%,10\%, and $15 \%$. Therefore, six scenarios of input data perturbation could be obtained by imposing the three percentages of changes to both the upstream and downstream conditions, as can be seen in Table 2. For scenarios 1-3, the downstream boundary was perturbed under $5 \%, 10 \%$, and $15 \%$ respectively; scenarios $4-6$ indicate the perturbation of the upstream boundary under 5\%,10\%, and $15 \%$ respectively.

Table 2. The sensitivity analysis scenarios for changing input of perturbed each boundary condition

Scenario number

Changes in the downstream boundary

conditions
4

5

6

1

2

3

$$
\begin{aligned}
& 5 \% \\
& 10 \% \\
& 15 \%
\end{aligned}
$$

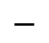

Changes in the upstream boundary

conditions

$5 \%$

$10 \%$

$15 \%$

Downstream perturbation

In order to perform the perturbation of the downstream boundary conditions, the maximum tide range for each month (in the year 2012) was obtained from the observed tide data (Figure 3). 


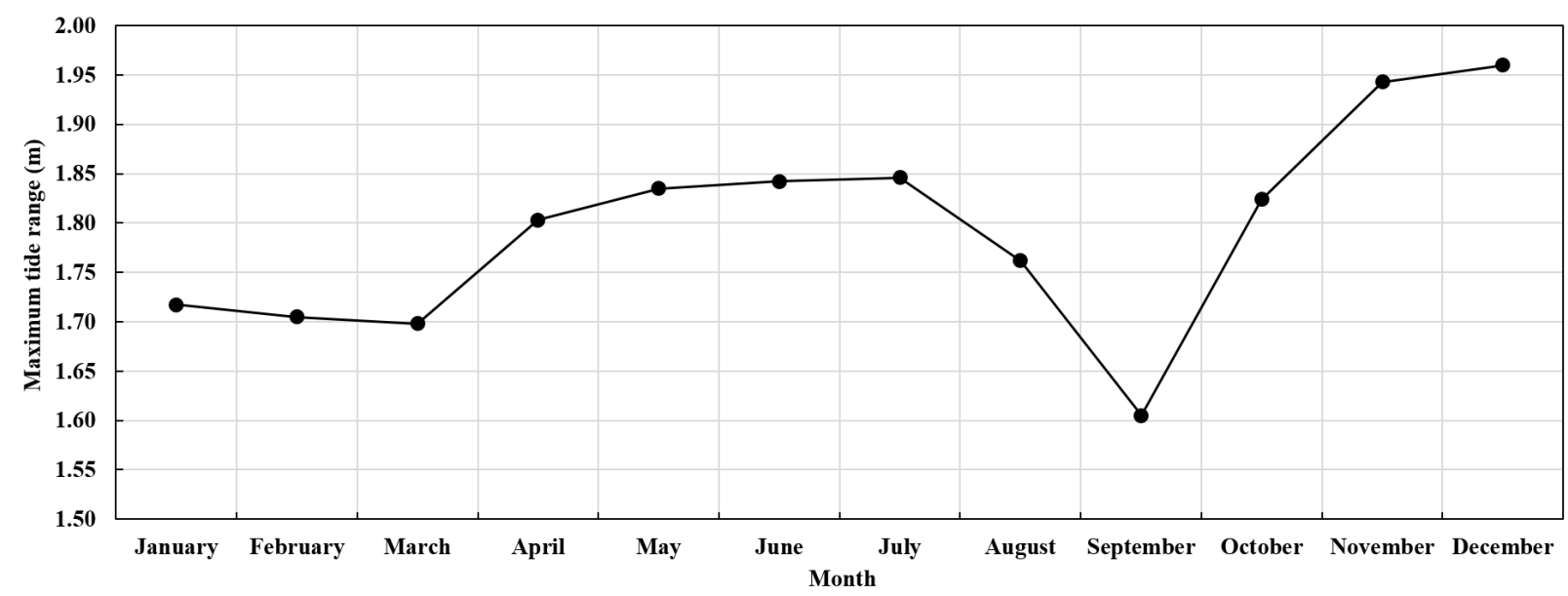

Figure 3. Maximum tide range of each month in the year 2012

Next, the maximum tide range of each month was perturbed by the relevant percentage $(5 \%, 10 \%$, and $15 \%$ ) in order to define a limit for generating random numbers. The lower and upper limit for the generation of random numbers under $5 \%, 10 \%$, and $15 \%$ changes in the downstream boundary are defined below, respectively $(i=0.05,0.10,0.15 ; j=1,2, \ldots, 12)$ :

$$
\left|\varepsilon_{i, j}\right| \leq A_{i} \cdot \eta_{\max (j)}
$$

in which $A_{i}=$ percentage of perturbation; $\varepsilon_{i, j}=$ generated random value for $A_{i}$ perturbation over the $j$ th month (m); and $\eta_{\max (j)}=$ maximum tide range for $j$ th month $(m)$. The random numbers were generated in the defined range (upper and lower limits) using Matlab, and then added to the observed water level data to produce the new downstream boundary conditions for the sensitivity analysis. The hydrodynamic.

\section{Upstream perturbation}

In terms of perturbation of the upstream boundary condition, the two peak floods of the year 2012 were selected to generate random numbers and impose changes in the upstream boundary conditions (Figure 4). Flood Event 1 (24/1/2012 3:00 AM - 26/1/2012 22:00 PM) has the maximum water level 
of $3.623 \mathrm{~m}$; and Flood Event 2 (17/1/2012 1:00 AM - 19/1/2012 12:00 AM) has the maximum water level of $1.183 \mathrm{~m}$.
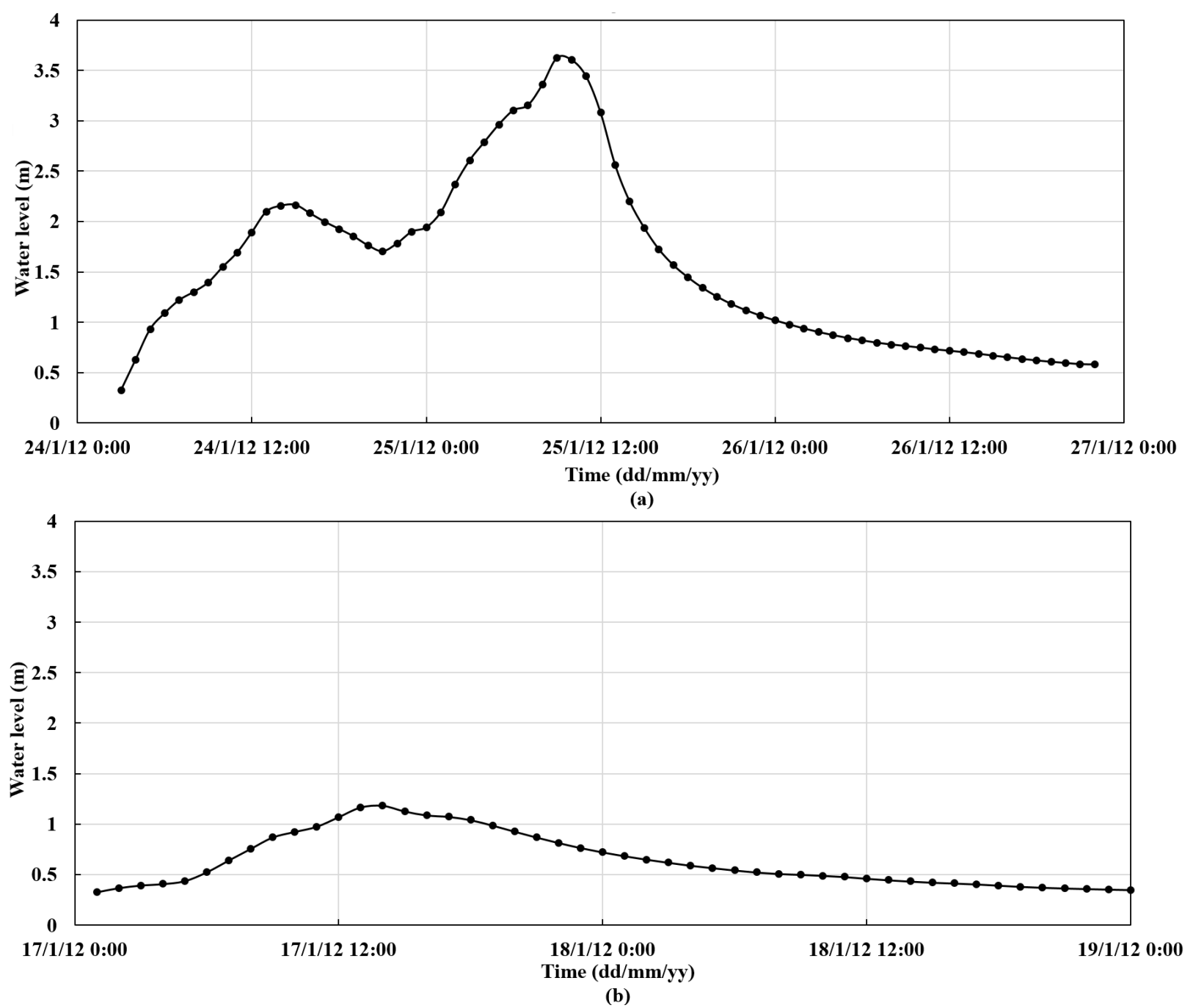

Figure 4. Hourly water level of the upstream boundary (Glenhurst station) over (a) Flood Event 1 and (b) Flood Event 2

The lower and upper limits for generating random numbers in Matlab under 5\%, $10 \%$, and $15 \%$ changes in the upstream boundary are defined as below, respectively $(k=1,2)$ :

$$
\left|\varepsilon_{i, k}\right| \leq A_{i} \cdot \eta_{\mathrm{PF}(k)}
$$

where $\varepsilon_{i, k}=$ generated random values for the $A_{i}$ perturbation over the $k$ th flood event $(m)$; and $\eta_{P F}$ $(k)=$ peak value of the $k$ th flood event $(m)$. The random numbers were produced within the defined 
range in Matlab. Next, these stochastic numbers were added to the observed water level over the flood event period to provide the new upstream boundary conditions for the sensitivity analysis.

\section{River model results}

\section{MIKE HYDRO River model setup}

Regarding model setup, the river network had to be initially digitized using a topographic base map and DEM data. For modelling process, the flow direction is defined positive and river type is taken regular. Next, the cross sections data were extracted along the river in order to analyse the results at different points of the river network. The cross sections are generated manually, thus, the distance between two successive cross sections is irregular. The minimum defined distance between two successive cross section is $47 \mathrm{~m}$ and the maximum distance is $1000 \mathrm{~m}$. During the next stage, the initial conditions of the river had to be set up by defining the simulation period (from 1/1/2012 14:00 to $31 / 12 / 20120: 00$ ), time steps ( $1 \mathrm{~min}$ ), and initial water level at the beginning of the simulation period (Carrara water level $=0.53 \mathrm{~m}$ ). The most important step of 1D HD model setup is the definition of accurate boundary conditions, including both upstream and downstream conditions. In the present case study, hourly water level records of the Glenhurst monitoring site in 2012 (Figure 5) were used as the time varying upstream open boundary condition, while hourly observed Gold Coast Seaway tides over the same year were defined as the time varying downstream open boundary condition. The observed tide values ranged from $-0.933 \mathrm{~m}$ to $1.32 \mathrm{~m}$ over the year 2012, and the mean water level was $0.116 \mathrm{~m}$ during the same period. 


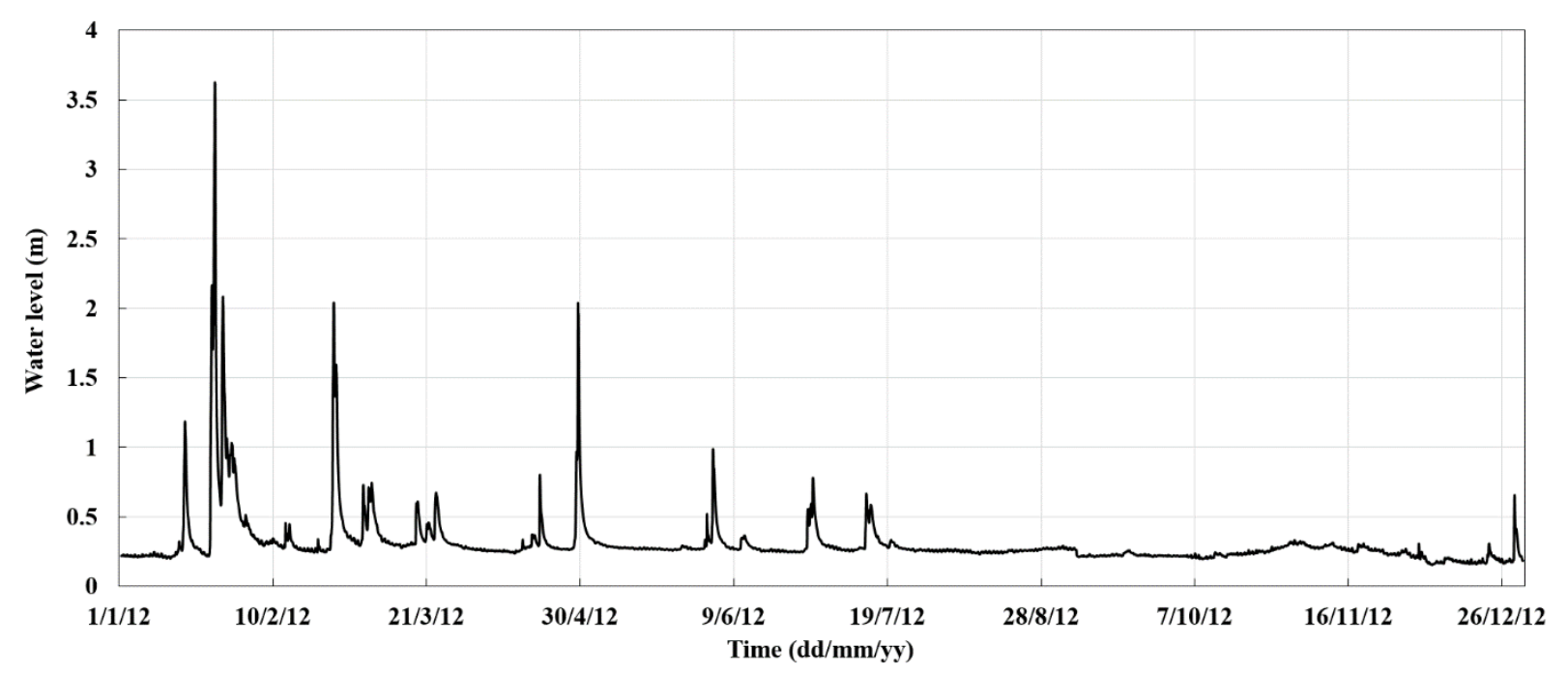

Figure 5. Hourly water level at the Glenhurst Station in 2012 over 1/1/2012 14:00-31/12/2012 $14: 00$

After setting up the mode, the next step was model calibration which is a process of varying the friction coefficient values to obtain the optimum levels of agreement between observations and model predictions. In the present paper, the model was calibrated using the hourly observed water levels from Carrara Alert site (1/1/2012 - 8/4/2012) (Figure 6). Moreover, Manning's coefficient friction and the hourly observed water level records of the Evandale Alert station (over five days) (Figure 7) were applied to validate the model. The available data for model calibration and validation are the water level time series of two gauging sites, as stated earlier.

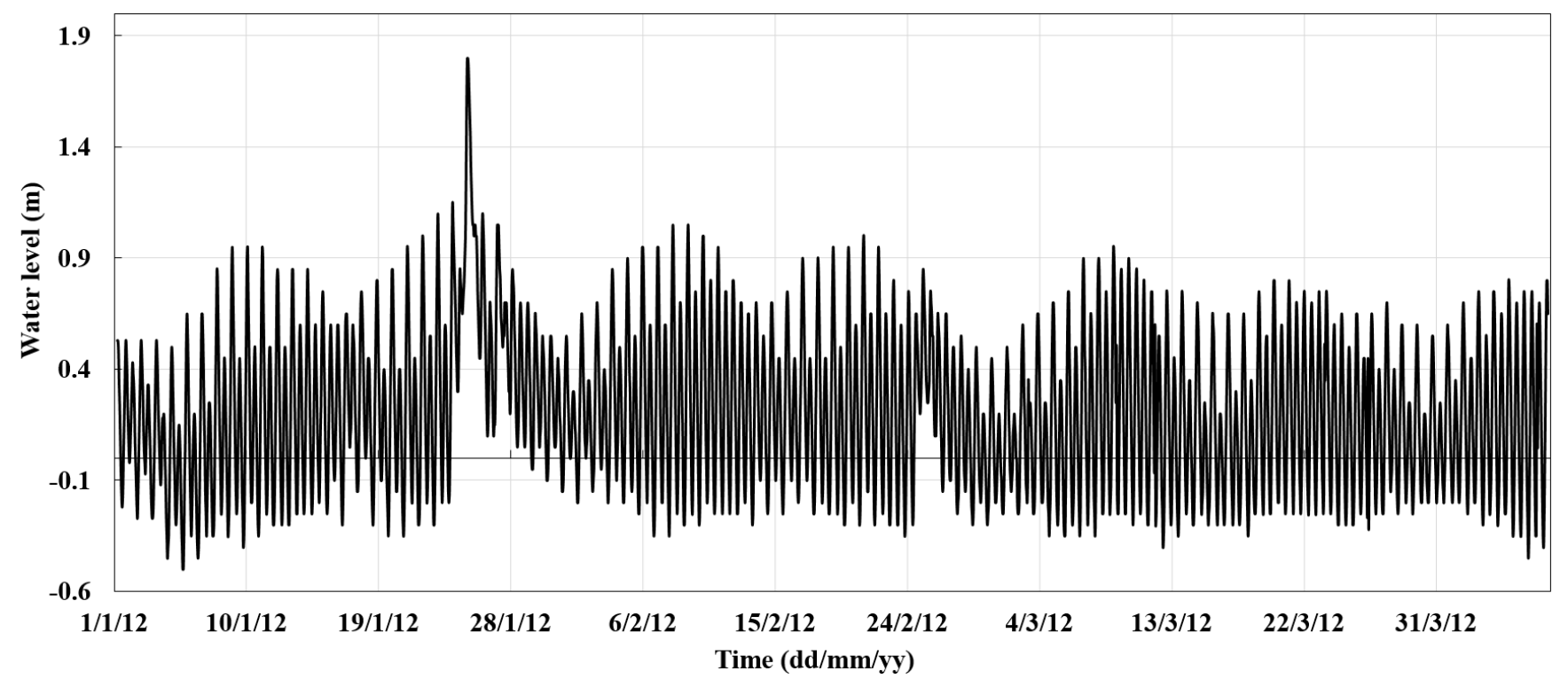

Figure 6. Hourly water level at Carrara Alert station over 1/1/2012-8/4/2012 


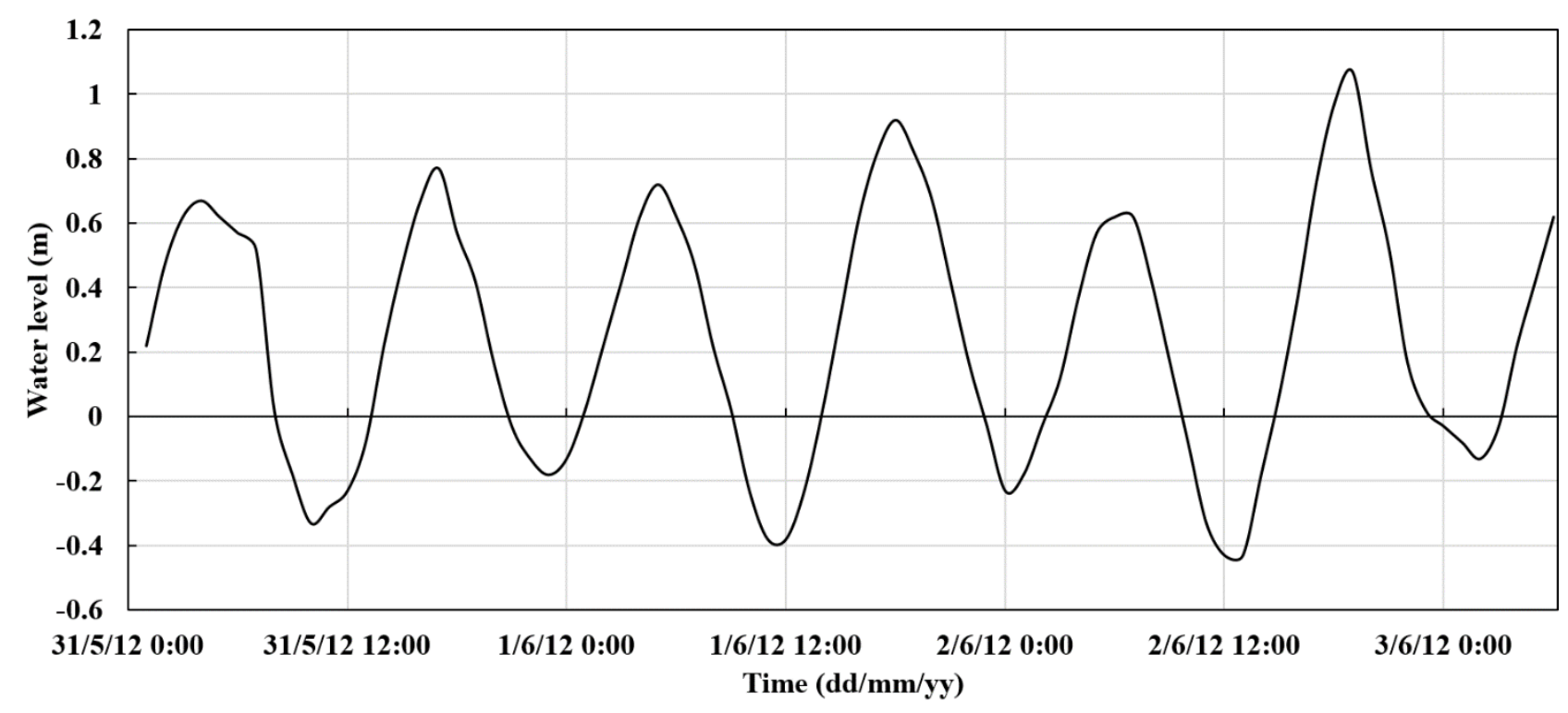

Figure 7. Hourly water level at Evandale Alert station over 31/5/2012 1:00-3/6/2012 6:00

After setting up the model, the next steps are model calibration and validation respectively. The results of these two steps are presented in the following sections.

MIKE HYDRO River model calibration

The hydrodynamic model can be calibrated using Manning's roughness. The Nerang River catchment is formed by the erosion of creek beds and subsequent depositing of sediment over heavy rainfall (GCCC 2011). The Nerang estuary has poor geomorphic value and substantial area has been reclaimed. The lower reaches of the Nerang River have ocean origin sediment and the riverbed is generally formed by non-cohesive sand material, with the mean particle size $0.29 \mathrm{~mm}$. Given that Nerang River estuary is a wave-dominated delta, this river has low sediment trapping efficient (Adair \& Rahman 2003). Initially, the model was simulated using the default value of Manning's roughness coefficient $(n=0.033)$ in MIKE HYDRO River. During the calibration process, Manning's roughness coefficient was calibrated to a uniform value to derive the best agreement between the observed and simulated water levels at the Carrara Alert site (chainage $7.52 \times 103 \mathrm{~m}$ ). The calibrated Manning's $\mathrm{n}$ values for different cross sections are presented in Table 3. 
Table 3. Manning's roughness coefficient for the Nerang River chainage

River chainage $\left(m \times 10^{3}\right)$

$0-7.52$

$7.62-22.50$
Manning's roughness coefficient $(n)$

0.013

0.011

The simulated water levels at the Carrara Alert site were compared to observed records (Figure 8) for three periods: (a) 2/1/2012 - 6/1/2012, (b) 23/1/2012 - 27/1/2012, and (c) 24/2/2012 - 28/2/2012. As can be seen, the Carrara Alert site appeared to be highly dominated by tidal influence, and the defined downstream boundary condition has a significant impact on the computed water levels of the Carrara Alert site. According to Figure 8, the simulated water levels are higher than those observed in most periods. This is due to the existence of canals and small branches reaching the Nerang River at different locations; these branches and canals have not been considered in the present research. Currently, limited available data at reaching points and canals have led to the existence mangrove canals being eliminated from the present study, which is the main reason for water level overestimations. As can be seen in figure $8(\mathrm{~b})$, the highest peak flow was underestimated by approximately $0.3 \mathrm{~m}$. It is worth noting that the number of data containing high flows were significantly lower than medium to low flow. Consequently, scarce peak water level data was available model calibration, which led to less efficient performance of the model over extreme events. Additionally, the measurement sensors of gauging stations might not measure the water level accurately over the flooding events. Therefore, such difference between observed and simulated peak might be also the result of poor and uncalibrated sensor measurements. However, a clear overall agreement between observed and simulated water level can be seen during the low to medium flow conditions. 


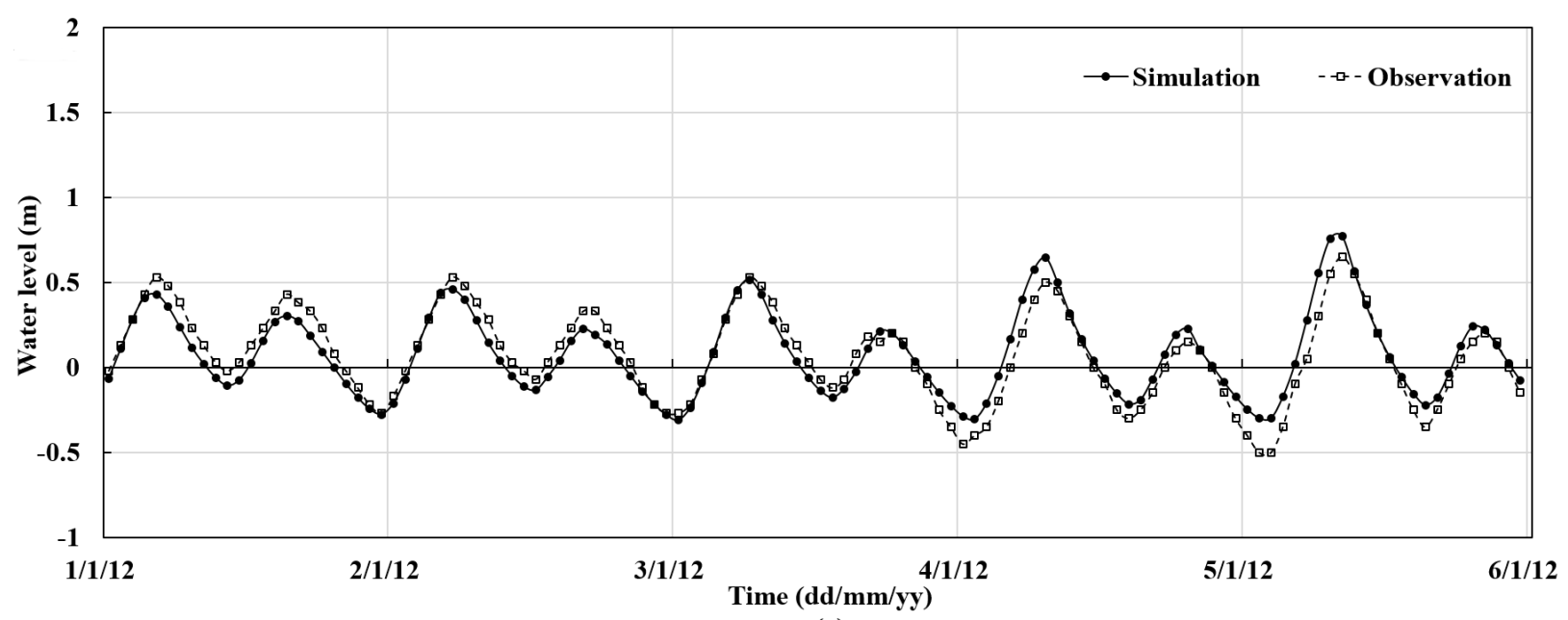

(a)

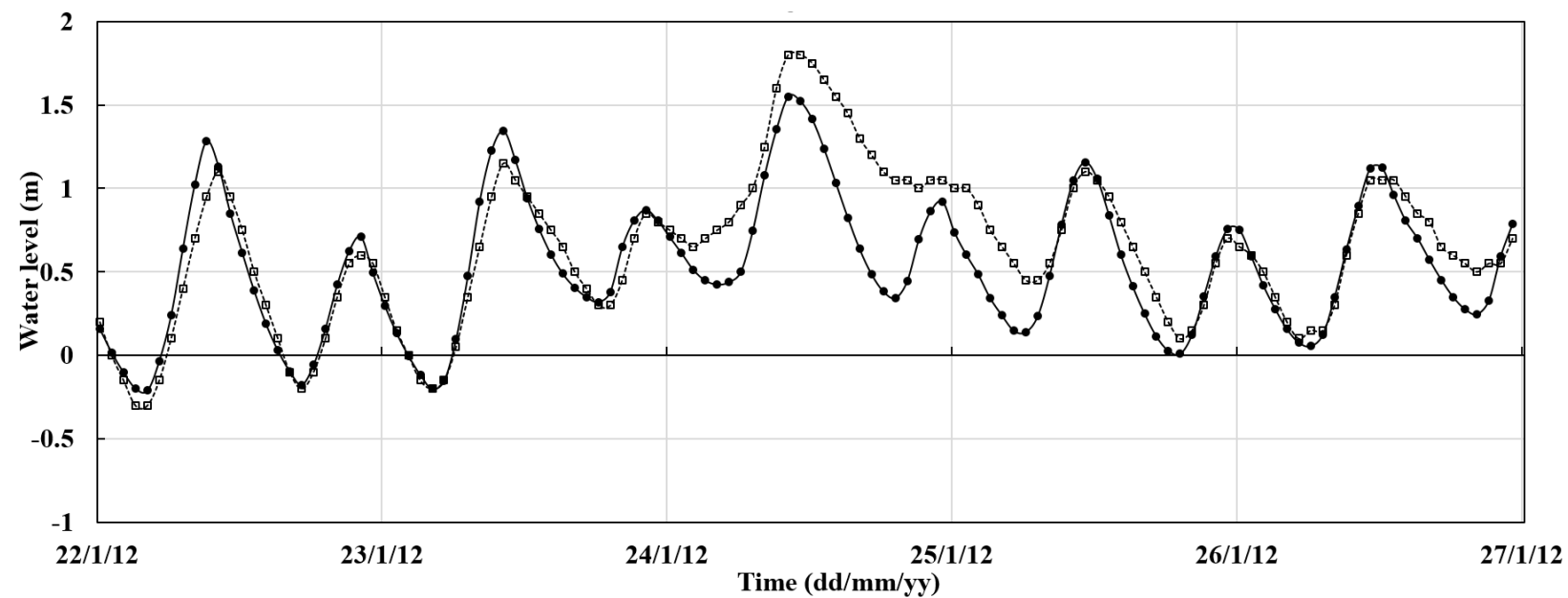

(b)

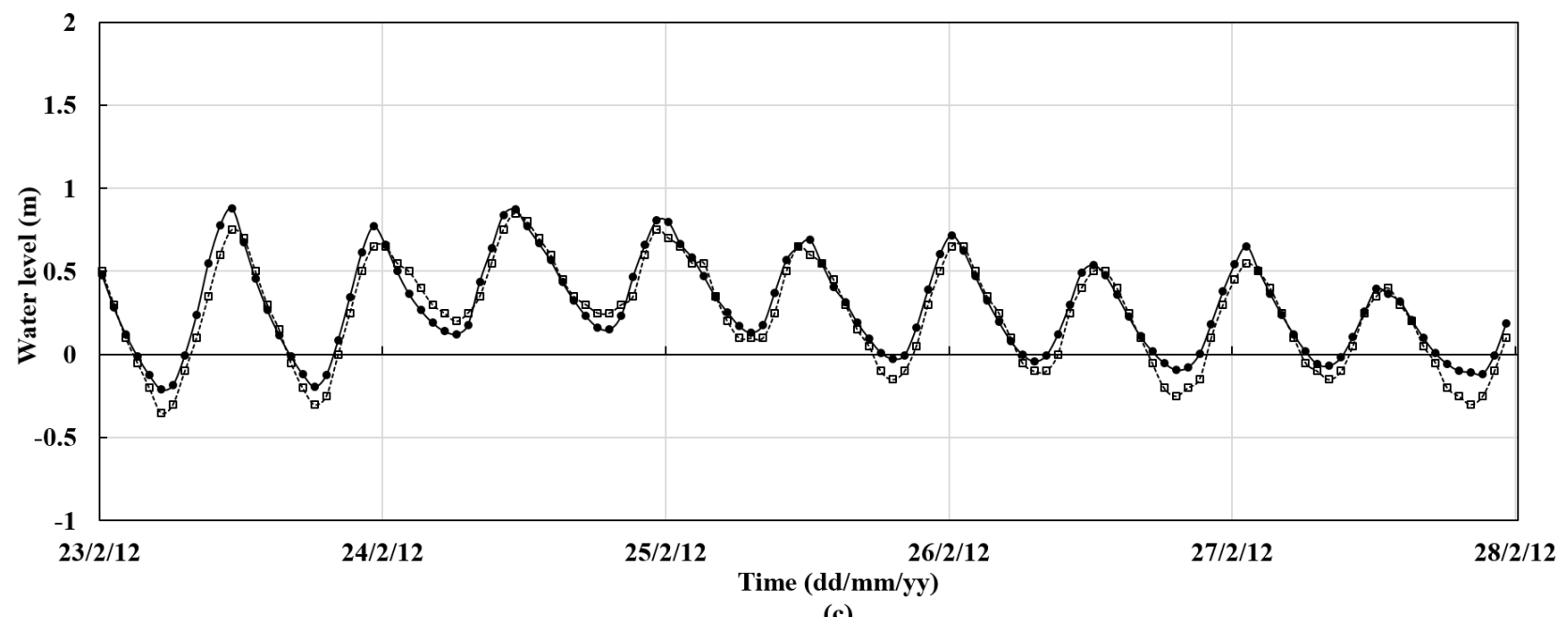

(c)

Figure 8. Comparison of observed and simulated hourly water levels at Carrara Alert site over period (a), (b), and (c) 
In order to analyse and test the model performance, indices needed to be defined. The performance indices used in this study are (1) correlation coefficient $\left(R^{2}\right) ;(2)$ Root Mean Square Error (RMSE); and (3) Nash-Sutcliffe efficiency coefficient (NSE) (Nash \& Sutcliffe 1970).

1. $R^{2}$ is defined as shown below:

$$
R^{2}=\frac{\sum_{i=1}^{n}\left(S_{i}-\mu_{s}\right)\left(O_{i}-\mu_{o}\right)}{(N-1) \sigma_{s} \sigma_{o}}
$$

where, $N=$ total number of observations; $\mu_{s}$ and $\mu_{o}=$ average of simulated and observed water level, respectively; $O_{i}=$ observed water level at the $i$ th hour; and $S_{i}=$ simulated water level at the $i$ th hour; and $\sigma_{s}$ and $\sigma_{o}=$ standard deviation of the simulated and observed water levels, respectively.

2. RMSE is defined as follows:

$$
R M S E=\sqrt{\frac{1}{N} \sum_{i=1}^{N}\left(O_{(i)}-S_{(i)}\right)^{2}}
$$

3. NSE is calculated as below:

$$
N S E=1-\frac{\sum_{i=1}^{N}\left(O_{(i)}-S_{(i)}\right)^{2}}{\sum_{i=1}^{N}\left(O_{(i)}-\mu_{o}\right)^{2}}
$$

Table 4 shows the estimated performance indices of the simulated results at the Carrara site, which confirm the reliability of the model. Pan et al. (2013) and Cho et al. (2013) have defined performance ratings for NSE. Based on their classification, $0.75<N S E \leq 1$ is rated very good, $0.65<N S E \leq 0.75$ is rated good, $0.5<N S E \leq 0.65$ is rated satisfactory, and NSE $\leq 0.5$ is rated unsatisfactory. According to Table 4, there is a good correlation between simulated and observed water levels as, typically, $R^{2}$ values greater than 0.5 are considered acceptable (Santhi et al. 2001; Van Liew et al. 2003). NSE is rated as very good, good, and very good for periods a, b, and c 
respectively. Period b refers to a flooding event, which is why it is classified in a good range rather than being in a very good range. The perfect fit for $R M S E$ is zero, therefore, periods a and $\mathrm{c}$ with the $0.10 \mathrm{~m}$ for $R M S E$ indicate very small disagreement between the observed and simulated results. In general, there is a close agreement between observed and simulated water levels, while the mentioned errors are due to eliminating canals and branches.

Table 4. Performance indices for Carrara Alert site during calibration for the year 2012

\begin{tabular}{cccc}
\hline Performance indices & Period a & Period b & Period c \\
\hline$R^{2}(\%)$ & 93.17 & 88.30 & 97.08 \\
$R M S E(m)$ & 0.10 & 0.27 & 0.10 \\
$N S E$ & 0.87 & 0.73 & 0.92 \\
\hline
\end{tabular}

MIKE HYDRO River model validation

After the model calibration, the MIKE HYDRO River model was validate using the hourly water level records from the Evandale Alert site (chainage 18552.3 $\mathrm{m}$ ) over five days (31/5/2012 1:00 AM3/6/2012 6:00 AM). Figure 9 indicates the compared water level values of the observation and simulation at Evandale Alert station during the validation period. It is apparent that both water level values fit very well. 


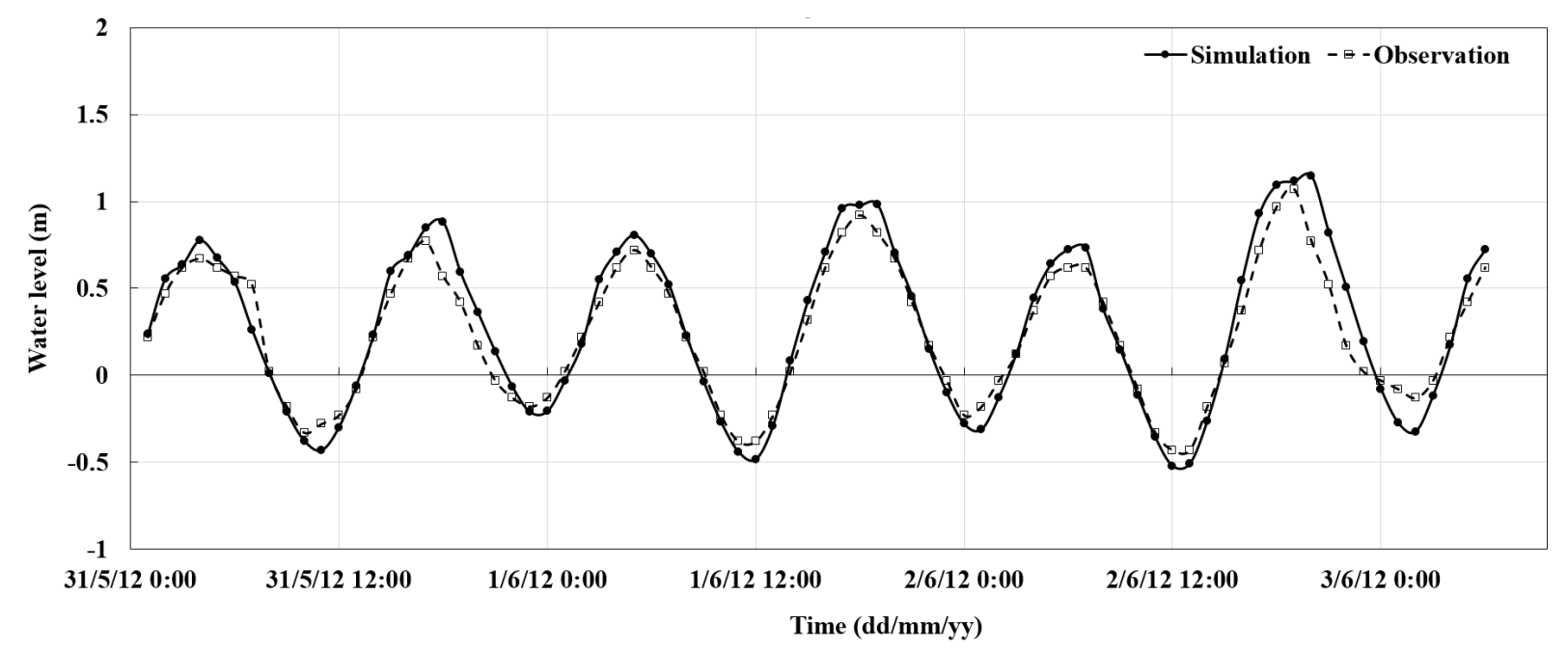

Figure 9. Comparison of hourly observed and simulated water levels at Evandale Alert site over 31/5/2012 1:00-3/6/2012 6:00

The performance indices of the validation period are presented in Table 5. Based on the stated performance rating, $R^{2}, R M S E$, and NSE are rated in the very good range. This shows that the calibrated model also performs well during the validation period.

Table 5. Performance indices for Evandale Alert site during calibration for the year 2012

Performance indices

$$
R^{2}(\%)
$$$$
\text { RMSE }(m)
$$

NSE

\section{Estimated values}

97.79

0.12

0.90

\section{Sensitivity analysis results}

In order to have better understanding of the impacts of the changed boundary conditions on the water level changes along the river, three points have been selected to show the sensitivity analysis results and to discuss the trend of water level changes along the river (Figure 10). The distance between these points and upstream are $3.13 \mathrm{~km}, 14.78 \mathrm{~km}$, and $20.21 \mathrm{~km}$ respectively. 


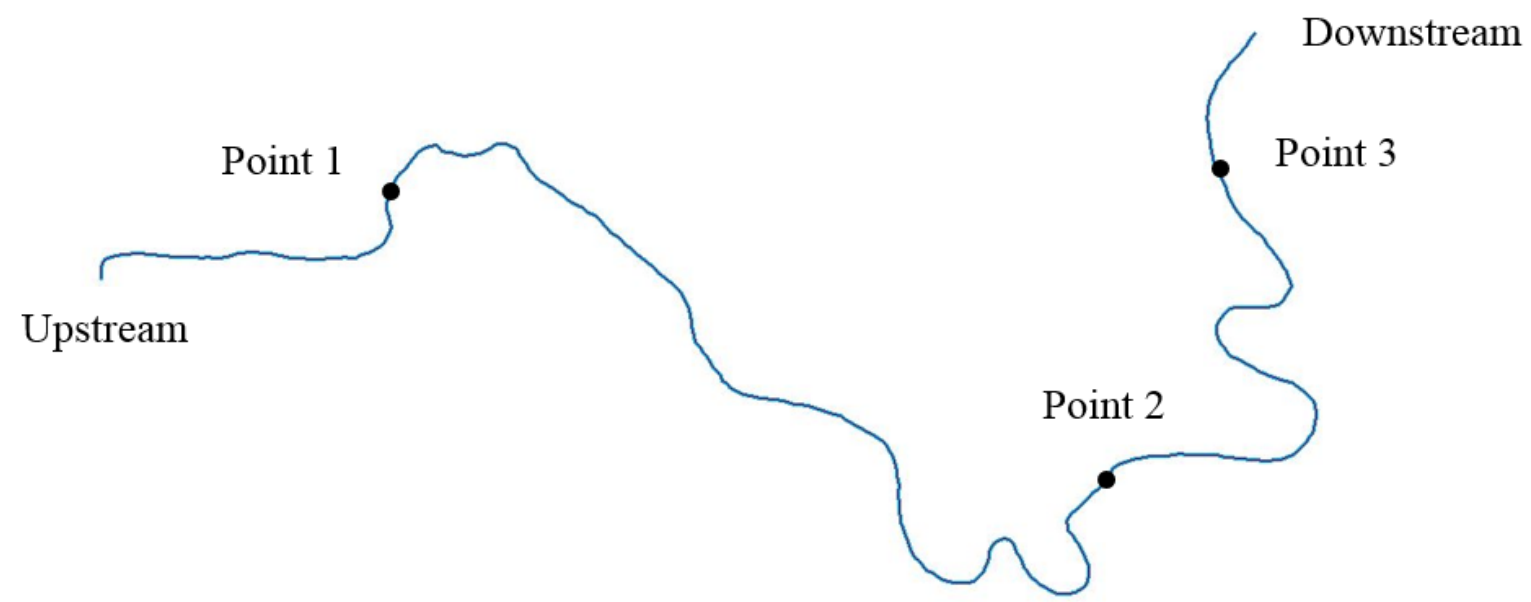

Figure 10. Three selected points for spatial the sensitivity analysis

The histogram of water level variations in the three mentioned points are shown in Figures 11 and 12 for changing downstream and upstream boundaries respectively. Figure 11 indicates the absolute value of the changes in water level relative to monthly maximum tide range under the changes in the downstream boundary over the year 2012. Figure 12 presents the absolute value of the changes in water level relative to maximum Flooding Event 1 (water level: $3.623 \mathrm{~m}$ ) over the period of the stated flood event (24/1/2012 3:00 AM - 26/1/2012 22:00 PM). 

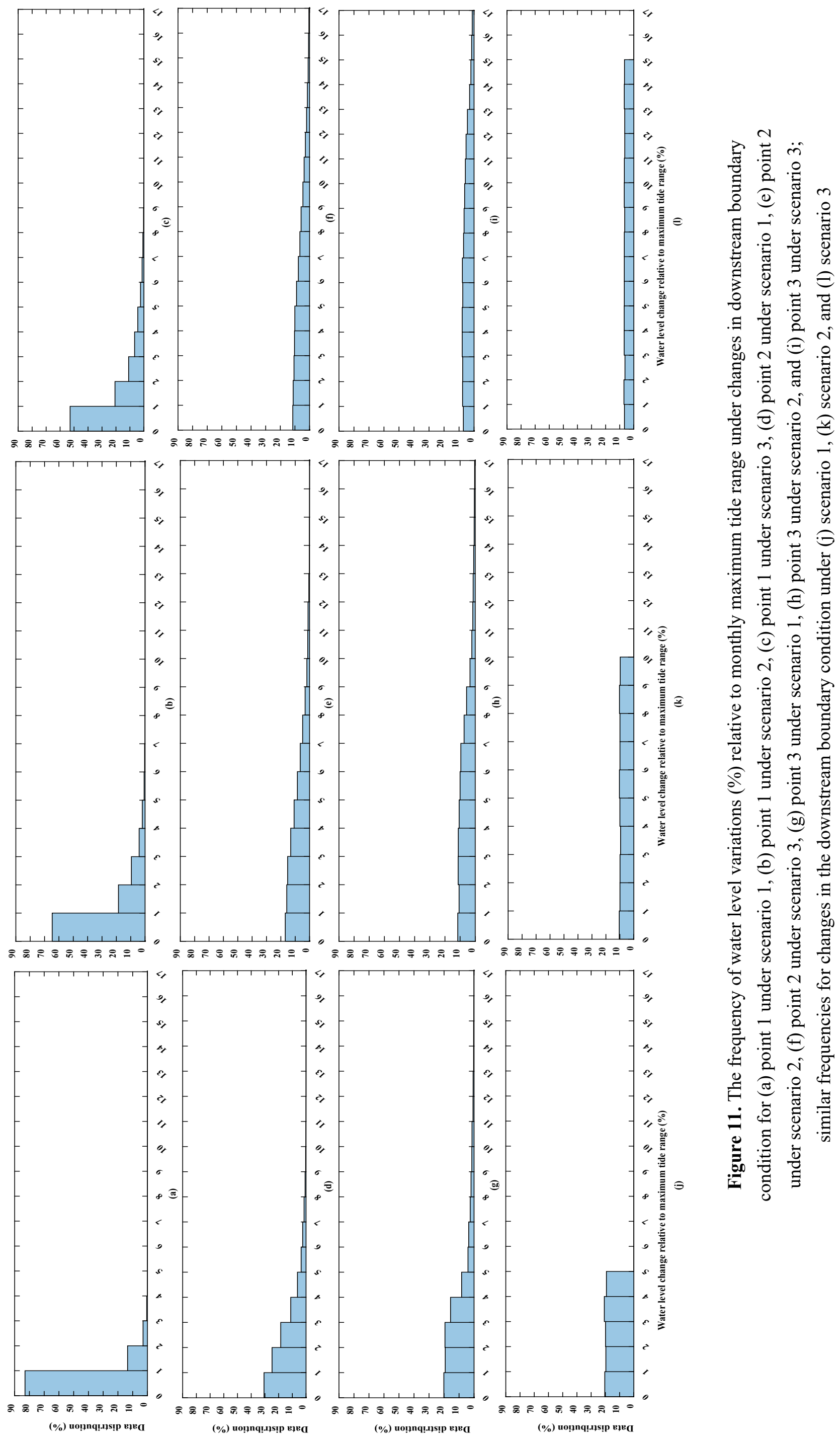

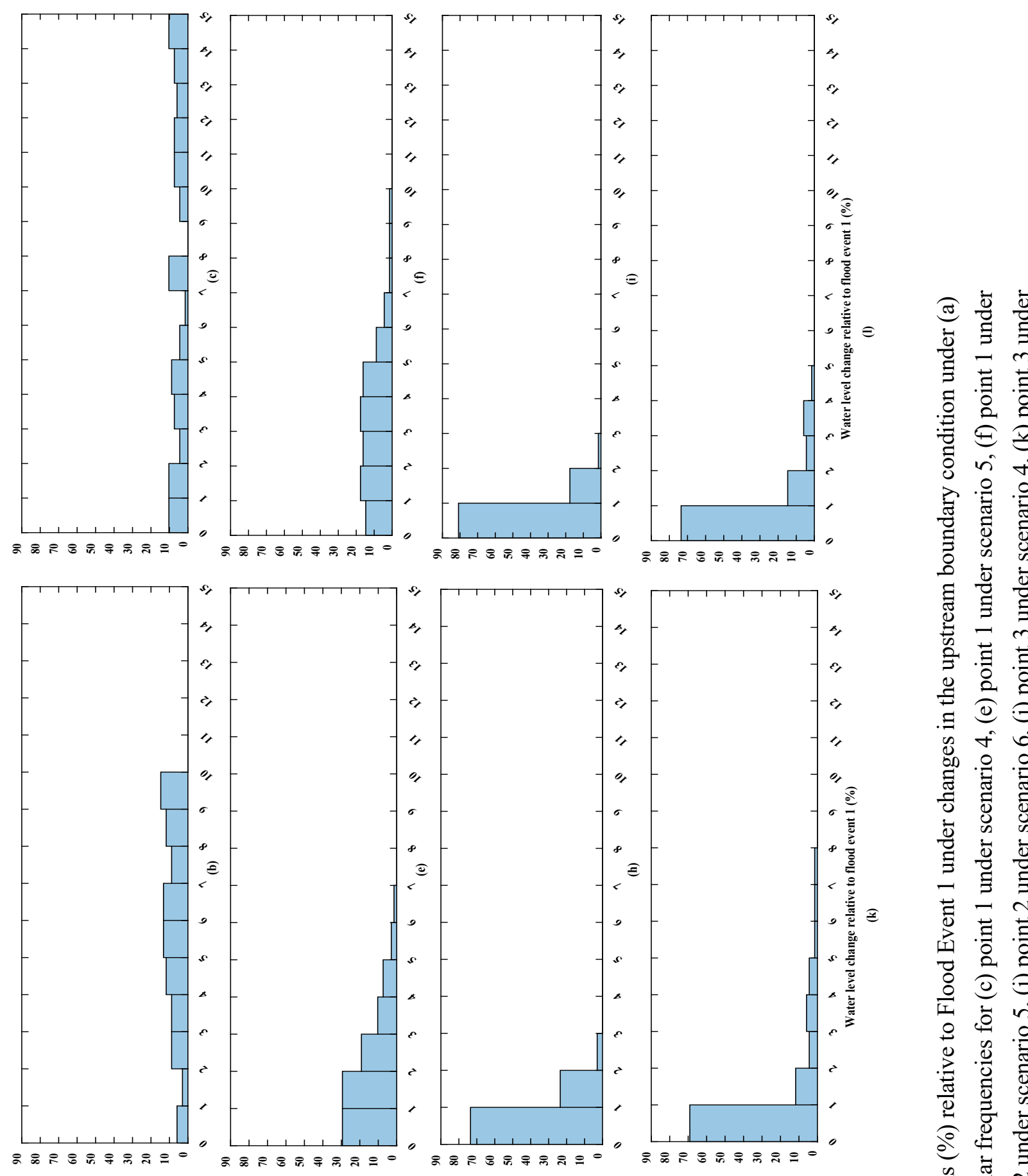

宽 윯 可

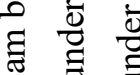

焉

‡

$\stackrel{2}{2}$

$\exists$ (

ऽ.

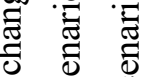

के

离

馬 $\stackrel{\Xi}{\Xi}$

岔言菩

उ.

它

$\stackrel{0}{0}$ 离

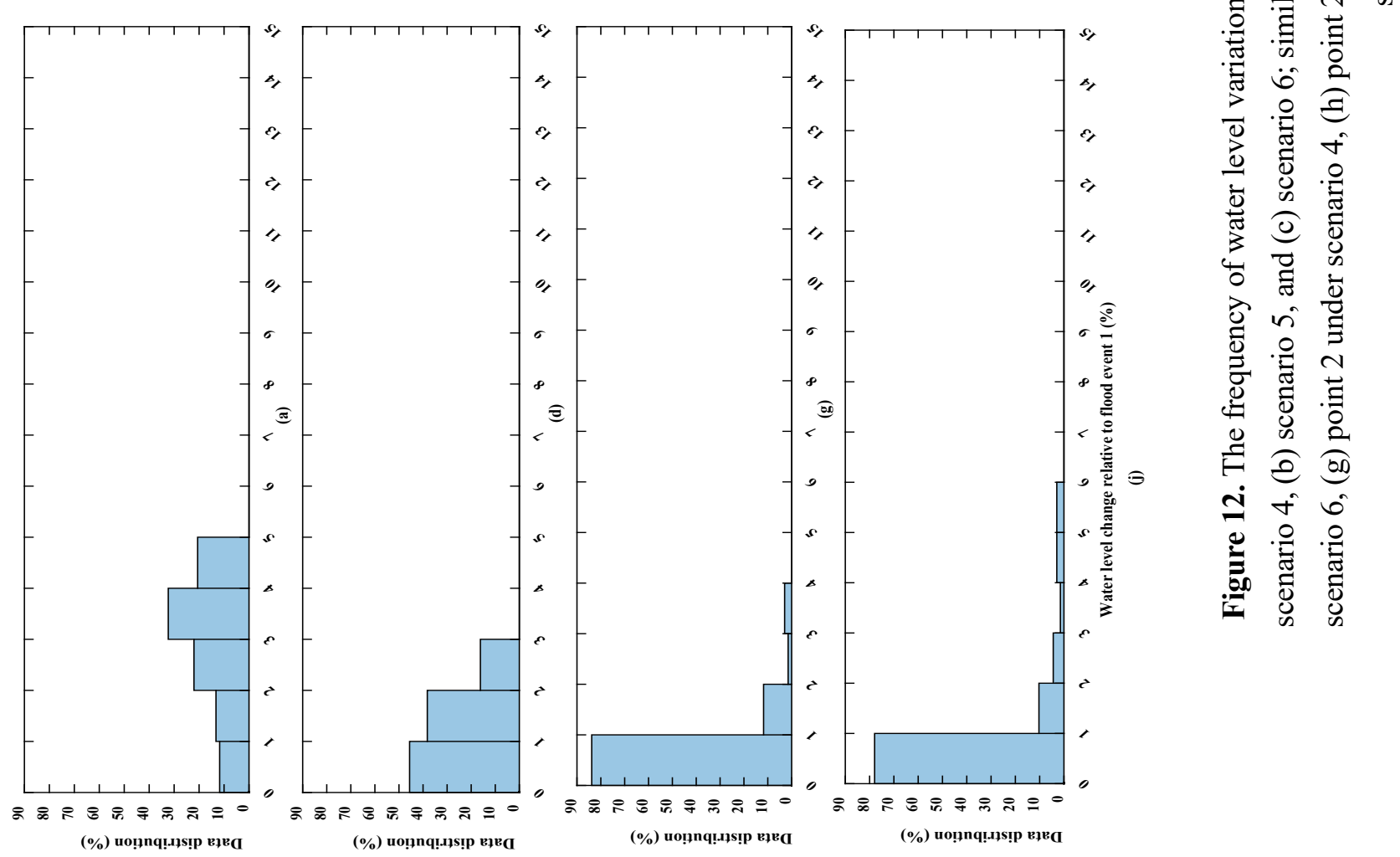


Figures 11(a), 11(b), and 11(c) present the histogram of frequency of water level changes for point 1, located upstream. It can be seen that the percentage of water level changes reaches $7 \%$ under $15 \%$ change (scenario 3) in the downstream boundary [Figure 11(c)], while the maximum distribution of water level under $5 \%$ change (scenario 1) is $3 \%$ [Figure 11(a)]. This means that the higher changes in the downstream boundary conditions affect more water level time series in point 1 . Additionally, if imposed downstream water level variations are 5\% (scenario 1), 10\% (scenario 2), and 15\% (scenario 3), [Figure 11(j), 11(k), and 11(1)], the corresponding water level variations in point 1 will reach maximum water level variations of 3\%, 5\%, and 7\%, respectively [Figure 11(a), 11(b), and 11(c)].

Similar to point 1 , the histogram of point 2 has the greatest spread under $15 \%$ change in the downstream boundary (scenario 3) [Figure 11(1)] as the water level variations reach 15\% [Figure 11(f)], while the 5\% changes in downstream [Figure 11(j)] lead to maximum variations of $8 \%$ for point 2 [Figure 12(d)]. At point 2, the water level varies by $8 \%, 12 \%$, and 15\% [Figure 11(d), 11(e), and 11(f)] when the downstream boundary is changed by $5 \%, 10 \%$, and $15 \%$, respectively. According to Figures 11(g), 11(h), and 11(i), the same trend can also be seen for point 3 , as the maximum water level variation can potentially reach $11 \%, 14 \%$, and $17 \%$ under $5 \%$ [Figure 11(j)], 10\% [Figure 11(k)], and 15\% [Figure 11(1)] changes in the downstream boundary, respectively. This indicates that under the condition of changing tide levels, point 3 shows much greater water level variations, which is the result of narrow river width at this point.

Comparing the water level variations of the three points [Figure 11(a), 11(d), and 11(g)] with the $5 \%$ change in the downstream boundary (scenario 1) [Figure 11(j)], the higher percentages of data (approximately $80 \%$ ) show water level variations between $0 \%$ and $1 \%$ in point 1 [Figure 11(a)], while almost $30 \%$ of data in point 2 [Figure $11(\mathrm{~d})$ ] and $20 \%$ of data in point 3 [Figure $11(\mathrm{~g})$ ] have water level variations between $0 \%$ and $1 \%$. It can be concluded that variations in the downstream boundary have minimal impact on upstream and stronger impact on neighbouring locations.

Figures 12(a), 12(b), and 12(c) indicate the changes of water level in the upstream boundary conditions (input data) under 5\% (scenario 4), 10\% (scenario 5), and 15\% (scenario 6) change over 24/1/2012 3:00 AM - 26/1/2012 22:00 PM period, respectively. Given that random numbers were applied to generate stochastic changes in the boundary, one of the bars has zero value [Fig. 12(c)], which 
means no data is changing in this specific range (8\%-9\%). This occurs due to the small number of changes over the limited period of the flood event (68 hours). Figures 12(d), 12(e), and 12(f) show the frequency of changes at point 1 under 5\%,10\%, and 15\% change respectively. It can be seen that the maximum percentages of water level variations are 3\% [Figure 12(d)], 7\% [Figure 12(e)], and 10\% [Figure $12(\mathrm{f})$ ] under $5 \%, 10 \%$, and $15 \%$ change of the upstream boundary respectively. Similar trends can be identified for points 2 and 3 as well. Therefore, based on the histogram of each point, it is concluded that there is greater distribution of the water level variations with the increased changes in the upstream boundary.

By comparing Figures 12 (d), 12(g), and 12(j), it can be understood that at point 1, almost $65 \%$ of data shows water level variation of more than $1 \%$ [Figure 12(d)] because this point is located near the changed boundary. In contrast, almost $80 \%$ of the data at points 2 and 3 [Fig. 12(g) and 12(j)] has a water level variation range of $0 \%-1 \%$ since these points are located further away from the changed boundary, and the impact of the boundary becomes weaker at points 2 and 3 . Similar trends can be seen by comparing Figures 12(e), 12(h), and 12(k) as well.

In general, comparing the same changed conditions in both downstream and upstream boundaries (Figure 11 and 12), it can be seen that point 1 is more sensitive to imposed changes in the upstream boundary condition since $10 \%$ change of downstream and upstream boundaries leads to maximum 5\% [Figure 11(b)] and 7\% [Figure 12(e)] water level variations respectively. In contrast, point 2 indicates more sensitivity to the changes in the downstream boundary, as $10 \%$ changes of the both downstream and upstream boundary conditions create maximum water level variations of $12 \%$ [Figure 11(e)] and $3 \%$ [Figure 12(h)] respectively. Finally, point 3 is more dominated by changes in tidal conditions (the downstream boundary) since maximum water level variations of $14 \%$ [Figure 11(h)] and $8 \%$ [Figure 12(k)] can be seen under $10 \%$ change in downstream and upstream boundaries respectively. Therefore, the middle part of the river is very sensitive to tidal conditions, and the variation of tidal level can potentially lead to even higher water level variations in the middle of the river.

It is worth to remarking that

As stated before, many literatures conduced common sensitivity analysis of boundary conditions in 1D hydrodynamic models through imposing a constant percentage of changes to the values of 
boundary conditions, while such constant variabilities are not likely in the natural river condition as changes of sea level and river flow are not following a specific constant trend (Norton \& Bradford 2009; Sun et al. 2012; De Paiva et al. 2013; Sarvia et al. 2017; Bruce et al. 2018; Islam et al. 2018). Therefore, the current study proposed a new sensitivity analysis approach, which provided in-depth understanding of changes in the river hydrodynamic conditions when random water level changes occur in sea level (downstream boundary) and river flow (upstream boundary condition). The methodology applied in this study, and also results might help policy makers and hydraulic modelers to set up and calibrate a hydrodynamic model for water level prediction at ungauged points of the river as well as quantifying and analysing the sensitivity of different points of the river to boundary conditions. Though we acknowledge that the results are variable at different regions, the introduced methodology to reach that results is general and applicable worldwide. It is worth remarking that the methodology and results of the current study may serve as a practical reference for hydrodynamic modeling of a tidal river and efficient sensitivity analysis.

\section{Conclusions}

This study addresses calibration, validation and sensitivity analysis of a 1D model called MIKE HYDRO River. This model is able to simulate complex and unsteady river flows. Considering the high records of flooding events, storm surges, and flood inundations in south east Queensland, particularly the Gold Coast City, determination of the hydraulic behavior of the lower Nerag River was essential. Additionally, probable sea level rise/variations can potentially affect the river flow conditions and flooding events in the studied tidal river. Thus, identification of such hydraulic behaviors at different points of the selected tidal river, particularly ungauged locations, benefit modellers with an efficient tool to predict the water level, and to address the potential damages of flood events and storm surges. Regarding the fact that the lower Nerang River is located in an urban estuary, determination of the hydraulic condition, particularly water level changes, at ungauged points of this river is crucial to address human losses over different river conditions. In this study, the hydrodynamic model was evaluated for the lower Nerang River, Australia for the purpose of 
presenting a practical reference for hydrodynamic modeling and food prediction as well as water level estimation at ungauged and sensitive points of the river.

The first purpose of this study was to calibrate and validate the hydrodynamic river model in order to predict water levels at ungauged points of the river. Once calibrated and validated, the model can be used for the purpose of minimizaing the probable damages of floods. Three performance indices $\left(R^{2}, R M S E\right.$, and NSE) were calculated to assess the model efficiency at Carrara Alert site and Evandale Alert site for calibration and validation periods, respectively. Results performance indices calculations indicated close agreement between the observed and simulated water levels over both calibration and validation periods.

The second purpose of this study was to evaluate the sensitivity of the model to the key input boundary conditions, both downstream and upstream water levels. Regarding the highly seasonal variations of river flow, and nonlinear and noise features of the hydrological time series, the sensitivity analysis was investigated based on adding stochastic terms (random noise) to the time series of boundary conditions. The sensitivity analysis was performed by comparing the frequency distribution of the water level variations with the frequency distribution initial condition of the tidal Nerang River. Six scenarios were defined based on 5\%,10\%, and $15 \%$ changes of water level in both downstream and upstream boundary conditions. The results indicated that the model is more sensitive to the river downstream boundary conditions, which confirmed that the studied flows domain of the river are determined by downstream tides. In order to have better understanding of the impacts of the changed boundary conditions, three points were selected along the river to investigate the model sensitivity: point 1,2, and 3 with $3.13 \mathrm{~km}, 14.78 \mathrm{~km}$, and $20.21 \mathrm{~km}$ away from the upstream boundary, respectively. Considering the three points under the same percentage of change in the downstream boundary, it is concluded that with increasing distance from the downstream boundary, less impact was observed on upstream water levels. Moreover, the middle part of the river was more sensitive to changes in the downstream boundary conditions than to changes in the upstream boundary conditions. The percentage of tidal level changes in downstream led to higher percentages of water level variations in the middle parts of the river (point 2) as 5\%,10\%, and $15 \%$ changes in the downstream boundary led to maximum water level variations of $8 \%, 12 \%$, and $15 \%$, respectively. Moreover, 
maximum water level variations at point 3 (lower part) can potentially reach $11 \%, 14 \%$, and $17 \%$ due to $5 \%, 10 \%$, and $15 \%$ downstream boundary changes, respectively. This confirms that the rate of water level changes in downstream boundary condition was seen to be increased (even doubled) in the lower part of the river.

The results of the current study demonstrated that the calibrated model is an efficient and easyto-apply tool for flow predictions of tidal rivers. Additionally, the random noise sensitivity analysis can equip modelers with a robust tool to assess the sensitivity of a model to input parameters, when parameters change randomly. By doing so, the importance of introducing accurate observed data into models can be assessed. In general, the outcomes of the present study will benefit future modeling efforts through provision of a useful modeling tool, which enables prediction of water level at ungauged points of the river under different flooding and climate change scenarios for the purpose of city planning and decision making. Concerning the future work and recommendations it would be interesting to:

- investigate the climate change impacts on sea level variations, and consequently water level variations over the tidal limit of a river;

- examine the results of the current study to consider different flood events;

- couple the current 1D model with a 2D model to determine the most efficient modeling approach; and

- consider the impacts of wind intensity and direction on water level.

\section{Acknowledgments}

Water level records at Evandale Alert site and DEM data have been provided by the Department of Environment and Resources Management and Geoscience Australia, respectively. The authors would like to acknowledge the support of the Water Monitoring Information Portal, Queensland Government, Australia, in their provision of the water level data, and of the Bureau of Meteorology, Australia, for providing Gold Coast Seaway tidal data and Carrara Water level data. The authors would also like to thank DHI for the freely provision of MIKE software for the current research. 


\section{Funding}

Funding for this project has been provided by Griffith University Postgraduate Research School through the GUPRS scholarship, and Griffith University International Postgraduate Research School through the GUIPRS scholarship.

\section{References}

Ardıçlığlu, M. \& Kuriqi, A. (2019). Calibration of channel roughness in intermittent rivers using HEC-RAS model: case of Sarimsakli creek, Turkey. SN Applied Science, 1, https://doi.org/10.1007/s42452-019-1141-9.

Abbs, D., McInnes, K. \& Raftar, T. (2007) The impact of climate change on extreme rainfall and coastal sea levels over south-east Queensland. Part 2: A High-Resolution Modelling Study of the Effect of Climate Change on the Intensity of Extreme Rainfall Events. CSIRO.

Adair, L. \& Rahman, A. (2003). Identification of erosion potential in an urban river in North Australia using GIS and hydrodynamic model. Proceeding of the Modeling and Simulation Society of Australia and Newzealand Inc, Jupiter Hotel and Casino, Townsville, Australia.

BOM (Bureau of Meteorology). (2017). Flood warning system for the Nerang river, Gold Coast, Australia.

Bates, P. D. (2004) Computationally efficient modelling of flood inundation extent, Proceedings of the Hydrological Risk, Cosenza, Italy, Brath, A., Montanari, A., Toth, E., Eds.

Bruce, L.C., Frassl, M.A., Arhonditsis, G.B., Gal, G., Hamilton, D.P., Hanson, P.C., et al. (2018) A multi-lake comparative analysis of the General Lake Model (GLM): Stress-testing across a global observatory network. Environmental Modelling and Software, 102, 274-291. 
Brunton, E. A., Srivastava, S. K., Schoeman, D. S. \& Burnett, S. (2018). Quantifying trends and predictors of decline in eastern grey kangaroo (Macropus giganteus) populations in a rapidly urbanising landscape. Pacific Conservation Biology, 24(1), 63-73.

Boulomytis, V. T. G., Zuffo, A. C., Filho, J. G. D. \& Imteaz, M. A. (2017). Estimation and calibration of Manning's roughness coefficients for ungauged watersheds on coastal floodplains. International Journal of River Basin Management, 15(2), 199-206.

Bai, R., Zhang, D. \& Jia, H. (2011). Factor sensitivity analysis with neural network simulation based on perturbation system. Journal of Computer, 6(7), 1402-1407.

Cho, J., Bosch, D., Vellidis, G., Lowrance, R. \& Strickland, T. (2012). Multi-site evaluation of hydrology component of SWAT in the coastal plain of southwest Georgia. Hydrological Process, 27(12), 1691-1700.

Chen, W. B., \& Liu, W. C. (2017). Modeling the influence of river cross-section data on a river stage using a two-dimensional/three-dimensional hydrodynamic model. Water, 9(3), https://doi.org/10.3390/w9030203.

DHI (Danish Hydraulic Institute). (2016). MIKE 11 hydrodynamic reference manual. Horsholm, Denmark.

Douben, K. J. (2006). Characteristics of river floods and flooding: a global overview, 1985-2003. Irrigation and Drainage, 55, S9-S21.

De Paiva, R. C. D., Buarque, D. C., Collischonn, W., Bonnet, M. P., Frappart, F., Calmant, S., et al. (2013). Large-scale hydrologic and hydrodynamic modeling of the Amazon River basin. Water Resources Research, 49(3), 1226-1243.

Dimopoulos, I., Chronopoulos, J., Chronopoulou-Sereli, A. \& Lek, S. (1999). Neural network models to study relationships between lead concentration in grasses and permanent urban descriptors in Athens city (Greece). Ecological Modelling, 120(2-3), 157-165. 
Dung, N. V., Merz, B., Bardossy, A., Thang, T. D. \& Apel, H. (2011). Multi-objective automatic calibration of hydrodynamic models utilizing inundation maps and gauge data. Hydrology and Earth System Sciences, 15(4), 1339-1354.

Fabio, P., Aronica, G. T. \& Apel, H. (2010). Towards automatic calibration of 2-D flood propagation models. Hydrology and Earth System Sciences, 14(6), 911-924.

Garson, G. D. (1991). Interpreting neural network connection weights. Artificial Intelligence Expert, 6(4), 47-51.

GCCC (Gold Coast City Council). (2006). Nerang River Integrated Catchment and Waterway Management Plan. Gold Coast, Australia: Mtchell, C., \& Oldridge, S.

GCCC (Gold Coast City Council). (2007). Hinze dam stage 3, Environmental impact statement supplementary report. Gold Coast, Australia.

GCCC (Gold Coast City Council). (2011). The Nerang River catchment study guide. Gold Coast, Australia.

GCCC (Gold Coast City Council). (2015). Nerang River Catchment, Hydrological Study. Gold Coast, Australia.

Hall, J. W., Boyce, S. A., Wang, Y., Dawson, R. J., Tarantola, S. \& Saltelli, A. (2009). Sensitivity analysis for hydraulic models. Journal of Hydraulic Engineering, 135(11), 959-969.

Herrnegger, M., Nachtnebel, H. P. \& Schulz, K. (2015). From runoff to rainfall: inverse rainfallrunoff modelling in a high temporal resolution. Hydrology and Earth System Sciences, 19(11), 46194639.

Islam, M. M. M., Hofstra, N., \& Sokolova, E. (2018). Modelling the present and future water level and discharge of the tidal Betna River. Geosciences, 8(8), https://doi.org/10.3390/geosciences8080271 
Jahandideh-Tehrani, M. Bozorg-Haddad, O. \& Loáiciga, H. A. (2019). Application of nonanimal-inspired evolutionary algorithms to reservoir operation: an overview. Environmental Monitoring and Assessment, 191, https://doi.org/10.1007/s10661-019-7581-2.

Kumar, M. (2018). River flow simulation using MIKE11 and SRTM DEM data: Case of Mahanadi Delta region in India. Annals of Plant and Soil Research, 20(2), 130-138.

Kim, B., Choi, S. Y. \& Han, K. Y. (2019). Integrated real-time flood forecasting and inundation analysis in small-medium streams. Water, 11(5), 919-938.

Leandro, J., Chen, A. A., Djordjevic, S., \& Savic, D. A. (2009). Comparison of 1D/2D coupled (sewer/surface) hydraulic models for urban flood simulation. Journal of Hydraulic Engineering, 135(6), 495-504.

Lek, S., Delacoste, M., Baran, P., Dimopoulos, I., Lauga, J. \& Aulagnier, S. (1996). Application of neural networks to modelling nonlinear relationships in ecology. Ecological Modelling, 90(1), 3952.

Mirfenderesk, H. (2009). Flood emergency management decision support system on the Gold Coast, Australia. Australian Journal of Emergency Management, 24(2), 17-24.

Merwade, V., Cook, A., \& Coonrod, J. (2008). GIS techniques for creating river terrain models for hydrodynamic modeling and flood inundation mapping. Environmental Modelling \& Software, 23(10-11), 1300-1311.

Mahmood, S., Rahman, A., \& Shaw, R. (2019). Spatial appraisal of flood risk assessment and evaluation using integrated hydro-probabilistic approach in Panjkora River Basin, Pakistan. Environmental Monitoring and Assessment, 191, https://doi.org/10.1007/s10661-019-7746-z.

Moradkhani, H., Sorooshian, S., Gupta, H. V. \& Houser, P. R. (2005). Dual state-parameter estimation of hydrological models using ensemble Kalman filter. Advances in Water Resources, 28(2), 135-147. 
Norton, G. E. \& Bradford, A. (2009). Comparison of two stream temperature models and evaluation of potential management alternatives for the Speed River, Southern Ontario. Journal of Environmental Management, 90(2), 866-878.

Nash, J. E. \& Sutcliffe, J. V. (1970). River flow forecasting through conceptual models, Part I A discussion of principles, Journal of Hydrology, 10(3), 282-290.

Pappenberger, F., Beven, K., Horritt, M. \& Blazkova, S. (2005). Uncertainty in the calibration of effective roughness parameters in HEC-RAS using inundation and downstream level observations. Journal of Hydrology, 302(1-4), 46-69.

Panda, R. K., Pramanik, N. \& Bala, B. (2010). Simulation of river stage using artificial neural network and MIKE 11 hydrodynamic model. Computers \& Geosciences, 36(6), 735-745.

Parhi, P. K., Sankhua, R. N. \& Roy, G. P. (2012). Calibration of channel roughness for Mahanadi river, (India) using HEC-RAS model. Journal of Water Resources and Protection, 4(10), 847-850.

Pan, T., Wu, S., Dai, E. \& Liu, Y. (2013). Estimating the daily global solar radiation spatial distribution from diurnal temperature ranges over the Tibetan Plateau in China. Applied Energy, 107, 384-393.

Rahman, M. M., Arya, D. S., Goel, N. K., \& Dhamy, A. P. (2011). Design Flow and Stage Computations in the Teesta River, Bangladesh, Using Frequency Analysis and MIKE 11 Modeling. Journal of Hydrologic Engineering, 16(2), 176-186.

Radwan, M., Willems, P. \& Berlamont, J. (2004) Sensitivity and uncertainty analysis for river quality modelling. Journal of Hydroinformatics, 6(2), 83-99.

Strelkoff, T. (1970). Numerical solution of Saint-Venant equations. Journal of Hydraulic Division, 96(1), 223-252. 
Santhi, C., Arnold, J. G., Williams, J. R., Dugas, W. A., Srinivasan, R. \& Hauck, L. M. (2001). Validation of the SWAT model on a large river basin with point and nonpoint sources. Journal of the American Water Resources Association, 37(5), 1169-1188.

Scardi, M. \& Harding, L.W. (1999). Developing an empirical model of phytoplankton primary production: a neural network case study. Ecological Modelling, 120(2-3), 213-223.

Sarvia, J. P., Lima, B. S., Gomes, V. M., Flores, P. H. R., Gomes, F. A., Assis, A. O., ... Calixto, W. P. (2017). Calculation of sensitivity index using one-at-a-time measure based on graphical analysis. Proceeding of the 18th International Scientific Conference on Electric Power Engineering (EPE), Kouty nad Desnou, Czech Republic, Publisher: IEEE.

Sun, X. Y., Newham, L. T. H., Croke, B. F. W. \& Norton, J. P. (2012). Three complementary methods for sensitivity analysis for water quality model. Environmental Modelling and Software, 37, $19-29$.

Tsai, L. Y., Chen, C. F., Fan, C. H. \& Lin, J. Y. (2017). Using HSPF and SWMM models in a high previous watershed and estimating their parameter sensitivity. Water, 9(10), 780-796.

Teng, J., Jakeman, A. J., Vaze, J., Croke, B. F. W., Dutta, D. \& Kim, S. (2017). Flood inundation modelling: a review of methods, recent advances and uncertainty analysis. Environmental Modelling and Software, 90, 201-216.

Tayfur, G., Kavvas, M. L., Govindaraju, R. S. \& Storm, D. E. (1993). Applicability of St. Venant equations for two dimensional overland flows over infiltrating rough surface. Journal of Hydraulic, 119(1), 51-63.

Van Liew, M. W., Arnold, J. G. \& Garbrecht, J. D. (2003). Hydrologic simulation on agricultural watersheds: choosing between two models. Transaction of the ASABE, 46(6), 1539-1551.

Vidal, J. P., Moisan, S., Faure, J. B. \& Dartus, D. (2005). Toward a reasoned 1D river model calibration. Journal of Hydroinformatics, 7(2), 91-104. 
Vijay, R., Sargoakar, A. \& Gupta, A. (2007). Hydrodynamic simulation of river Yamuna for riverbed assessment: A case study of Delhi Region. Environmental Monitoring and Assessment, 130(1-3), 381-387.

Wang, X., Liu, T., Shang, S., Yang, D. \& M. Melesse, A. (2010). Estimation of design discharge for an ungauged overflow-receiving watershed using one-dimensional hydrodynamic model. International Journal of River Basin Management, 8(1), 79-92.

Wang, J. S., Ni, H. G. \& He, Y. S. (2000). Finite-difference TVD scheme for computation of dam-break problems. Journal of Hydraulic Engineering, 126(4), 252-262.

Wu, W., Rodi, W. \& Wenka, T. (2000). 3d numerical modelling of flow and sediment transport in open channels. Journal of Hydraulic Engineering, 126(1), 4-15.

Wang, A. \& Solomatine, D. P. (2019). Practical experience of sensitivity analysis: comparing six models, on three hydrological models, with three performance criteria. Water, 11(5), 1062-1088.

Whitehead, P. \& Young, P. (1979). Water quality in river systems: Mont Carlo analysis. Water Resources Research, 15(2), 451-459.

Warmink, J.J., Van der Klis, H., Booij, M.J. \& Hulscher, S. J. M. H. (2011). Identification and quantification of uncertainties in a hydrodynamic river model using expert opinions. Water Resources Management, 25(2), 601-622.

Xu, Z., Xiong, L., Xu, J., Cai, X., Chen, K. \& Wu, J. (2019). Runoff simulation of two typical urban green land types with the Stormwater Management Model (SWMM): sensitivity analysis and calibration of runoff parameters. Environmental Monitoring and Assessment, 191, 343-358. 